\title{
Scaling and Design Analyses of a Scaled-down, High-temperature Test Facility for Experimental Investigation of the Initial Stages of a VHTR Air- ingress Accident
}

David J. Arcilesi Jr. ${ }^{\mathrm{a}, *}$, Tae Kyu Ham ${ }^{\mathrm{a}}$, In Hun Kim ${ }^{\mathrm{a}}$, Xiaodong Sun ${ }^{\mathrm{a}}$, Richard N. Christensen ${ }^{\mathrm{a}}$, Chang H. Oh ${ }^{\mathrm{b}}$

${ }^{a}$ Nuclear Engineering Program, The Ohio State University, Columbus, OH 43210, USA

${ }^{\mathrm{b}}$ Idaho National Laboratory, Idaho Falls, ID 83402, USA

arcilesi.1@,osu.edu, ham.47@,osu.edu, kim.4704@,osu.edu, sun.200@,osu.edu, christensen.3@osu.edu

*Corresponding author at: The Ohio State University, $201 \mathrm{~W} 19^{\text {th }}$ Ave., Columbus, OH 43210 , USA. Tel.: +1 614247 4684; fax: +1 6142923163.

E-mail address: arcilesi.1@osu.edu 
Keywords: VHTR, HTGR, air ingress accident, density-driven stratified flow, molecular diffusion, natural circulation

\section{Introduction}

The potential for an air-ingress accident stems from consideration of a postulated loss-of-coolant accident in a Very High-Temperature Gas-cooled Reactor (VHTR). It is considered to be one of the most important safety issues for the VHTRs and, therefore, needs to be examined carefully for the reactor safety analysis (Oh et al., 2006). This accident is initiated by a break in the hot duct of the reactor cross vessel. In the worst-case scenario, the hot duct is completely severed and the reactor pressure vessel is disjoined from the energy conversion unit in what is referred to as a double-ended guillotine break. Following the break, a rapid depressurization of the vessel occurs. This leads to the ingress of an air-helium mixture into the reactor vessel. Since oxygen chemically reacts with high-temperature graphite, this could lead to damage of in-core graphite structures and fuel, release of carbon monoxide and carbon dioxide, core heat up, failure of the structural integrity of the system, and eventually the release of radionuclides to the environment. Therefore, the air-ingress accident scenarios and phenomena are very important to VHTR safety analysis.

Initially, the air-ingress mechanism was considered to be controlled by molecular diffusion when a one-dimensional (1D) numerical tool was used in the analysis (Oh et al., 2006; Hishida and Takeda, 1991; Takeda and Hishida, 1996; Kim et al., 2008; No et al., 2008). According to these studies, when the air-ingress speed is controlled by molecular diffusion, governed by Fick's law, the onset of global natural circulation in the reactor vessel takes on the order of 100 hours to occur after the break is initiated. This type of scenario would give the reactor operators a considerable amount of time to mitigate an accident scenario. 
However, more recent studies have shown that the previous work in which the air-ingress mechanism is dominated by molecular diffusion might misrepresent what will actually occur during an accident scenario (Oh et al., 2008, 2009; Oh and Kim, 2011). These recent studies show that the air ingress process might be controlled by a density-driven stratified flow of the hot helium and a relatively cold air-helium mixture. This generally happens when a heavy fluid (relatively cold air-helium mixture) in the reactor cavity intrudes into a light fluid (hot helium) in the hot exit plenum. These recent studies also show that the density-driven air ingress (DDAI) leads to another type of natural circulation whose flow path passes through the hot duct-hot exit plenum system of the VHTR as illustrated in Fig. 1. This localized natural circulation event is referred to as hot plenum natural circulation and is a distinct phenomenon from the previously mentioned global natural circulation. When DDAI dominates, three-dimensional (3D) computational fluid dynamic (CFD) models have estimated that the expected time for the onset of global natural circulation would be significantly reduced to $100 \mathrm{~s}$ (Oh and Kim, 2011). Meanwhile, two-dimensional (2D) simulations performed with the GAMMA code show that the onset of global natural circulation might commence as long as 500 hours after the accident initiation (Jin et al., 2011, 2012). Based on these results, it is possible that the accident scenario and the time scale for accident-mitigating procedures could be drastically altered from the molecular diffusion-dominated scenario.

Fig. 1. (a) GT-MHR reactor vessel and (b) enlarged hot duct-hot exit plenum system

In this study, CFD numerical simulations have provided considerable insight on how the airingress phenomena may behave for different hot duct break scenarios. It would be advantageous to develop an extensive experimental database for the air-ingress phenomena. These data will provide a more accurate understanding of the phenomena associated with the air-ingress 
accident; demonstrate which phenomenon, molecular diffusion or DDAI, will dominate for a given hot duct break geometry and orientation; and provide experimental data for the validation of CFD analyses. Therefore, in an effort to achieve these objectives, a $1 / 8^{\text {th }}$ scaled-down (by height and diameter) test facility design has been proposed as an integral test facility that is modeled after the hot duct-hot exit plenum system of a VHTR as shown in Fig. 1(b). Calculations show that the Rayleigh number based on the plenum's height of the prototypic hot duct-hot exit plenum system is on the order of $10^{9}$ at prototypic temperatures. The Rayleigh number of the $1 / 8^{\text {th }}$ scaled-down test facility design is on the order of $10^{6}$. The difference of these two Rayleigh numbers is three orders of magnitude; however, both numbers are within the laminar natural convection range. Therefore, the basic natural convection phenomenology can be preserved in a $1 / 8^{\text {th }}$ scaled-down model. From these calculations, a $1 / 8^{\text {th }}$ scale is optimal for the purpose of these experiments because it results in a facility that is economical and whose physical size is small enough to fit in the lab, while still being able to preserve the natural convection phenomenology of the prototypic system. The proposed scaled-down test facility is a reduced-pressure, reduced-temperature facility rated at $0.343 \mathrm{MPa}$ and $538^{\circ} \mathrm{C}$. The operating pressure and the core exit temperature of the prototypic VHTR design are $7 \mathrm{MPa}$ and $850^{\circ} \mathrm{C}$, respectively. Helium and air will be used as the gas species in the test facility. Since these are the same gas species utilized in the prototypic case, no fluid-to-fluid scaling analysis is necessary for this facility.

The proposed design of the scaled-down test facility is primarily two vessels joined by a duct with a flanged connection as shown in Fig. 2(a). The left vessel of Fig. 2(a) is the so-called containment vessel, which models the reactor containment. The right vessel of Fig. 2(a) is the main test vessel. This vessel is the scaled-down model of the VHTR hot duct-hot exit plenum 
system. Two heads are attached to the top and bottom of the hot exit plenum to maximize the thin-walled vessel's capacity to withstand pressure. Nozzles are welded to the top, bottom, and side of the main test vessel to allow observation of and instrumentation and heaters to be inserted into the hot exit plenum. The hot exit plenum in the main test vessel is separated from the upper and lower heads of the vessel by two steel plates as shown in Fig. 2(b). These plates also secure IG-110 graphite cylinders/shells which are located in the hot exit plenum. The hexagonal arrangement of the graphite cylinders/shells is illustrated in Fig. 2(c).

Fig. 2. (a) Side view of scaled-down test facility (b) cut view of main test vessel and (c) top view of hot exit plenum in main test vessel

For the design of the proposed test facility, hydraulic similarity is maintained by identically preserving the Froude number and by nearly matching the resistance number of the prototypic design. The aforementioned non-dimensional numbers follow from the scaling analysis performed on the hot duct-hot exit plenum system. The details of the scaling analysis and design analyses are presented in the following order: (i) geometric scaling analysis on the system; (ii) time scale analysis of the air-ingress phenomena; (iii) transient depressurization analysis of the reactor vessel; (iv) hydraulic similarity of the test facility; (v) heat transfer characterization for the hot plenum; (vi) power scaling analysis for reactor system; and (vii) design analysis of containment vessel. The aforementioned analyses are not in-depth calculations that accurately simulate the progression of the VHTR air-ingress accident. Instead, these analyses are detailed design calculations that serve as justification for the design and operation of the proposed test facility so that properly scaled phenomenology can be generated during the experiments. In each of the developmental analyses, the design calculations are a combination of a theoretical scaling analysis, hand calculations, MATLAB code calculations, and, where applicable, computational fluid dynamic calculations using ANSYS Fluent CFD software. 


\section{Geometric Scaling Analysis for a VHTR}

A unified description of the prototype reactor parameters is presented. The geometry and operating conditions are then used to develop a scaling analysis for DDAI and hot plenum natural circulation flow.

\subsection{Reactor Design Parameters}

Fundamental to the design and construction of a scaled-down experimental facility is an understanding of the design specifications and geometry of the prototype facility. An extensive literature review was performed to locate available information on the geometry of a representative VHTR design. In this study, the gas-turbine modular helium reactor design (GTMHR) 600 MWth developed by General Atomics is adopted as a reference design (General Atomics, 1996). A schematic of the core design is shown in Fig. 3.

Fig. 3. The gas-turbine modular helium reactor with key parameters indicated (Oh et al., 2008)

Furthermore, General Atomics (1996) gives the core power, core inlet and outlet temperatures, core helium mass flow rate, vessel dimensions, shutdown cooling system dimensions, control rod assembly housing dimensions, and hot duct and cold duct dimensions. In Oh et al. (2011), Kodochigov et al. (2002), MacDonald et al. (2003), Shaber et al. (2003), Neylan et al. (1994), Tak et al. (2008), McEligot et al. (2005), and Reza et al. (2006), additional design parameters and dimensions of the prototype facility are located. A list of the key dimensions of the pressure vessel is given in Table 1.

Table 1

List of key dimensions for GT-MHR pressure vessel

The key dimensions listed in Table 1 give a physical description of the VHTR pressure vessel and are instructive for providing the overall length scale of the reactor. However, the geometry 
of interest in the pressure vessel for the physical setup of this integral-effect experimental study is the hot duct and hot exit plenum. A close-up view of the hot duct-hot exit plenum system and its location in the pressure vessel are shown in Fig. 1. The process by which the hot duct length, support column diameter, and support column pitch are determined, as shown in parentheses in Table 1, is discussed in detail in Section 3.3.

\subsection{Geometric Scaling Analysis of the Reactor System}

A geometric scaling analysis is derived for the scaled-down test facility, which is based on a scaling analysis introduced by Reyes et al. (2010). From the continuity equation, the mass flow rate at every cross-section for the $i^{\text {th }}$ segment along the loop is constant for a steady-state process. Mathematically,

$$
\dot{m}=\dot{m}_{i}
$$

where $\dot{m}$ : mass flow rate and $\dot{m}_{i}$ : mass flow rate of the $i^{\text {th }}$ segment. The differential continuity equation for the hot side is

$$
\frac{\partial \rho_{H}}{\partial t}+w_{H} \frac{\partial \rho_{H}}{\partial z}+\rho_{H} \frac{\partial w_{H}}{\partial z}=0
$$

where $t$ : time, $z:$ axial variable, $\rho_{H}$ : average fluid density inside the reactor's hot exit plenum and $w_{H}$ : average fluid velocity inside the reactor's hot exit plenum. Similarly, the differential continuity equation for the cold side is

$$
\frac{\partial \rho_{C}}{\partial t}+w_{C} \frac{\partial \rho_{C}}{\partial z}+\rho_{C} \frac{\partial w_{C}}{\partial z}=0
$$

where $\rho_{C}$ : average fluid density inside the reactor's enclosure and $w_{C}$ : average fluid velocity inside the reactor's enclosure. The integrated loop momentum equation is written as follows:

$$
\frac{\mathrm{d} \dot{m}}{\mathrm{~d} t} \sum_{i} \frac{l_{i}}{a_{i}}=\left(\rho_{C}-\rho_{H}\right) g H-\frac{\dot{m}^{2}}{\rho_{r} a_{r}^{2}} \sum_{i} \frac{1}{2}\left(\frac{f l}{d_{h}}+K\right)_{i}\left(\frac{a_{r}}{a_{i}}\right)^{2}
$$


where $l_{i}$ : length of the $i^{t h}$ segment; $a_{i}$ : cross-sectional area of the $i^{\text {th }}$ segment; $H$ : vertical distance between the thermal centers of the hot and cold side; $\rho_{r}$ : average fluid density of the reference segment; $a_{r}$ : cross-sectional area of the reference segment; $f:$ Darcy friction factor of the $i^{\text {th }}$ segment; $d_{h}$ : hydraulic diameter of the $i^{\text {th }}$ segment; and $K$ : minor (form) loss coefficient in the $i^{\text {th }}$ segment.

The loop momentum equation can be made dimensionless by normalizing the terms relative to their initial conditions or boundary conditions. The parameters at the initial conditions are denoted by the subscript "o". That is,

$$
\begin{gathered}
H^{+}=\frac{H}{H_{o}} \\
\dot{m}^{+}=\frac{\dot{m}}{\dot{m}_{o}}=\frac{\dot{m}}{\rho_{r} a_{r} w_{o}} \\
\rho_{H}^{+}=\frac{\rho_{H}}{\left(\rho_{C}-\rho_{H}\right)_{o}} \\
\rho_{C}^{+}=\frac{\rho_{C}}{\left(\rho_{C}-\rho_{H}\right)_{o}} \\
{\left[\sum_{i} \frac{1}{2}\left(\frac{f l}{d_{h}}+K\right)_{i}\left(\frac{a_{r}}{a_{i}}\right)^{2}\right]^{+}=\frac{\sum_{i} \frac{1}{2}\left(\frac{f l}{d_{h}}+K\right)_{i}\left(\frac{a_{r}}{a_{i}}\right)^{2}}{\left[\sum_{i} \frac{1}{2}\left(\frac{f l}{d_{h}}+K\right)_{i}\left(\frac{a_{r}}{a_{i}}\right)^{2}\right]_{o}}}
\end{gathered}
$$

Substituting these ratios into the governing equations yield the following dimensionless equations:

$$
\begin{gathered}
\frac{\partial \rho_{H}^{+}}{\partial t^{+}}+w_{H}^{+} \frac{\partial \rho_{H}^{+}}{\partial z^{+}}+\rho_{H}^{+} \frac{\partial w_{H}^{+}}{\partial z^{+}}=0 \\
\frac{\partial \rho_{C}^{+}}{\partial t^{+}}+w_{C}^{+} \frac{\partial \rho_{C}^{+}}{\partial z^{+}}+\rho_{C}^{+} \frac{\partial w_{C}^{+}}{\partial z^{+}}=0
\end{gathered}
$$




$$
\frac{d \dot{m}^{+}}{d t^{+}}=\Pi_{L}\left[\frac{\left(\rho_{C}^{+}-\rho_{H}^{+}\right) H^{+}}{\Pi_{F r}}-\left(\dot{m}^{+}\right)^{2} \Pi_{F}\left[\sum_{i} \frac{1}{2}\left(\frac{f l}{d_{h}}+K\right)_{i}\left(\frac{a_{r}}{a_{i}}\right)^{2}\right]\right]
$$

The non-dimensional time scale is given as follows:

$$
t^{+}=\frac{t}{\tau}=\frac{t w_{o}}{H_{o}}
$$

where $w_{o}$ : velocity of the reference section at the onset of natural circulation and $H_{o}$ : geometric height of the reference section. The non-dimensional groups are defined wherein the length or geometric scale, the Froude number and the resistance number are given as follows:

$$
\begin{gathered}
\Pi_{L}=\frac{H_{o}}{a_{r} \sum_{i} \frac{l_{i}}{a_{i}}} \\
\Pi_{F r}=\frac{\rho_{r} w_{o}^{2}}{\left(\rho_{C}-\rho_{H}\right)_{o} g H_{o}} \\
\Pi_{F}=\left[\sum_{i} \frac{1}{2}\left(\frac{f l}{d_{h}}+K\right)_{i}\left(\frac{a_{r}}{a_{i}}\right)^{2}\right]
\end{gathered}
$$

\section{Scaled-down Test Facility Design Analyses}

Utilizing the scaled-down geometry and scaling analysis, a time scale analysis of the air-ingress phenomenon is derived for both the prototypic (GT-MHR) and scaled-down hot duct-hot exit plenum system. The total time scale of the air-ingress phenomenon is then compared to the time scale of the vessel depressurization. During the very brief time of the depressurization, the helium temperature inside the vessel decreases rapidly due to the helium expansion but quickly increases back to its original temperature due to heating from the high-temperature solid mass of the vessel and its internals. The high-temperature helium inside the vessel and the relatively cool air-helium mixture in the reactor cavity both at near the atmospheric pressure provide the initial conditions for the early stages of the air-ingress accident, which is driven by either density- 
driven stratified flow or molecular diffusion depending on the break geometry and orientation. To ensure minimal distortion between the flow phenomenology inside the hot duct-hot exit plenum system of the prototype and scaled-down geometry, an analysis is performed to scale the support column diameter and pitch by an appropriate factor to establish hydraulic similarity. This is important since the hydraulic similarity has a direct effect on the fidelity of the time scale similarity between the prototype and scaled-down system. Therefore, in order to maintain a high level of confidence in the similarity of the time scale analysis, a careful analysis of the hydraulic similarity must be performed.

\subsection{Time Scale Analysis of Air-ingress Phenomenon}

The total time scale of the air-ingress phenomena is derived from considering the individual time scales of three separate phenomena: density-driven stratified flow, natural circulation, and diffusion. Other phenomena such as thermal radiation and heat conduction from the core to the hot exit plenum, and heat generation from chemical reaction between graphite and air in the hot exit plenum were considered as significant potential influences on the total time scale of the airingress phenomena. However, calculations show that they do not contribute a significant amount of heat to the hot exit plenum relative to the amount of heat stored in the hot exit plenum's support columns during the initial stages of the air-ingress transient. This suggests that they do not have a significant effect on the total time scale of the air-ingress phenomena.

First, the time scale for density-driven stratified flow, $\tau_{D D}$, is calculated. This calculation is similar to the one performed by $\mathrm{Oh}$ and $\mathrm{Kim}$ (2011). The speed of the gravity current, $U$, for $0<\gamma<0.281$ is calculated using the following relation given by Lowe et al. (2005):

$$
U=\sqrt{(1-\gamma) g H}\left[\frac{1}{\gamma} \frac{h_{L}}{H}\left(2-\frac{h_{L}}{H}\right) \frac{1-h_{L} / H}{1+h_{L} / H}\right]^{1 / 2} \quad(\mathrm{~m} / \mathrm{s})
$$


where $\gamma$ : density ratio $\left(\rho_{1} / \rho_{2}\right) ; g$ : acceleration due to gravity $\left(\mathrm{m} / \mathrm{s}^{2}\right) ; H$ : channel depth $(\mathrm{m})$; and $h_{L}$ : current depth $(\mathrm{m})$. The ratio of the current depth to channel depth as a function of density ratio is shown in Fig. 4. Table 2 summarizes the conditions, current depth, and current speed for the prototypic and scaled-down case. The current speed of the prototypic case is almost three times greater than the current speed of the scaled-down case.

Fig. 4. Flow depth of the heavy current (Lowe et el., 2005)

\section{Table 2}

Gravity current speed and depth for air-ingress accident time scale analysis

To determine the DDAI time scale, a length scale was taken to be one-half of the hot exit plenum total length. This is equal to $L_{D D}=3.4 \mathrm{~m}$ for the prototype geometry and $L_{D D}=0.425 \mathrm{~m}$ for the scaled-down geometry. In this analysis, the DDAI time scale is compared to the diffusion time scale, which assumes that the air is uniformly spread throughout the height of duct cross section (Oh and Kim, 2011). In order to achieve a time scale that would allow a direct comparison with the molecular diffusion, a superficial air velocity was computed for the DDAI phenomenon. The superficial air velocity is defined as the gravity current velocity reduced by a ratio of the gravity current height to the channel height. This superficial air velocity preserves the amount of air that ingresses into the vessel during a hypothesized DDAI event if the height of the air propagating into the vessel at the superficial air velocity is the channel height (which is the condition with molecular diffusion). The superficial air velocity, $U_{s}$, is calculated from the speed of the gravity current as:

$$
U_{s}=\frac{U h_{L}}{H} \quad(\mathrm{~m} / \mathrm{s}) .
$$


The superficial air velocity comes out to be $0.211 \mathrm{~m} / \mathrm{s}$ for the prototype geometry and $0.071 \mathrm{~m} / \mathrm{s}$ for the scaled-down geometry. This results in a mass flow rate of $0.442 \mathrm{~kg} / \mathrm{s}$ for the prototypic conditions and $0.0023 \mathrm{~kg} / \mathrm{s}$ for the scaled-down conditions. Therefore, the minimum DDAI time scale, $\tau_{D D}$, is calculated by

$$
\tau_{D D}=\frac{L_{D D}}{U_{s}},
$$

which equals $16.08 \mathrm{~s}$ for the prototype geometry and $5.97 \mathrm{~s}$ for the scaled-down geometry. For the prototypic conditions, $7.11 \mathrm{~kg}$ of air ingresses into the vessel during the prototypic DDAI time scale. For the scaled-down conditions, $0.014 \mathrm{~kg}$ of air ingresses into the vessel during the scaled-down DDAI time scale.

Second, the time scale for the natural circulation phenomenon, $\tau_{\text {thermal }}$, is calculated. Using a $1 \mathrm{D}$ support column temperature profile analysis, as will be explained in Section 3.4, the Biot number of the graphite support column is calculated for different far-field air-helium gas mixture temperatures, $T_{i n f}$, and different air mole ratios of the air-helium gas mixture. Fig. 5 shows the average Biot number distribution for the prototypic geometry and prototypic temperatures $\left(T_{\text {top }}=\right.$ $850^{\circ} \mathrm{C}$ ). This temperature, $T_{\text {top }}$, is based on the core exit temperature of the helium coolant (General Atomics, 1996). Since the average temperature of the air-helium mixture in the hot plenum is not known, a parametric study is performed for different air-helium gas mixture temperatures, $T_{i n f}$, from 20 to $500^{\circ} \mathrm{C}$. The average Biot number, under these prototypic conditions, ranges from 0.0020 to 0.0066 . These values are on the order of $10^{-3}$, which falls in the regime of the lumped capacitance model since $\mathrm{Bi}<<1$.

Fig. 5. Average Biot numbers for prototypic conditions 
Similarly, Fig. 6 shows the average Biot number distribution for the scaled-down geometry and scaled-down temperatures $\left(T_{\text {top }}=750^{\circ} \mathrm{C}\right)$. The average Biot number, under these scaled-down conditions, ranges from $7.6 \mathrm{e}-4$ to 0.0022 , which again falls in the regime of the lumped capacitance model since $\mathrm{Bi}<<1$.

Fig. 6. Average Biot numbers for scaled-down conditions

The average Biot number of the graphite support column, for both the prototypic and scaleddown conditions, is on the order of $10^{-4}-10^{-3}$. Therefore, the error associated with using the lumped capacitance method is negligible. In this regime, the thermal time constant, which describes how quickly the temperature of the support column approaches the temperature of the surroundings, is given by the following relation:

$$
\tau_{\text {thermal }}=\frac{\rho V c_{p}}{h A_{s}},
$$

where $h$ : natural convection heat transfer coefficient $\left(\mathrm{W} / \mathrm{m}^{2}-\mathrm{K}\right) ; \rho$ : support column density $\left(\mathrm{kg} / \mathrm{m}^{3}\right) ; V$ : support column volume $\left(\mathrm{m}^{3}\right) ; c_{p}$ : support column specific heat capacity $(\mathrm{J} / \mathrm{kg}-\mathrm{K})$; and $A_{s}$ : support column surface area $\left(\mathrm{m}^{2}\right)$.

The average thermal time constants for a wide range of far-field temperatures $\left(20-500^{\circ} \mathrm{C}\right)$ and air mole fractions (0-1) are calculated for both the prototypic and scaled-down geometries and are shown in Figs. 7 and 8, respectively. Since the exact value of the thermal time constant is not nearly as important as its order of magnitude, an arithmetic average of the 11 values corresponding to a different air mole fraction value when the far-field temperature is $20^{\circ} \mathrm{C}$ is calculated. The thermal time constants for the 11 values correspond to the minimum thermal time constants for a given air mole fraction. Therefore, the average thermal time constant 
calculated in this analysis is a minimum average thermal time constant, and has a value of 14,008 s for the prototype geometry and 3,299 s for the scaled-down geometry.

Fig. 7. Average thermal time constant for prototypic conditions

Fig. 8. Average thermal time constant for scaled-down conditions

Finally, the time scale for the air-helium diffusion phenomenon, $\tau_{\text {Diff }}$, is calculated. To calculate the diffusion time scale, the binary diffusion coefficient, $D_{A B}$, and length scale, $L_{D i f f}$, should be determined. The theoretical expression of the diffusion coefficient for binary gas mixtures of nonpolar, non-reacting molecules at low to moderate pressures can be estimated by kinetic theory. An equation attributed to Chapman and Enskog (Chapman and Enskog, 1970) results in the following relation:

$$
D_{A B}=1.8583 \times 10^{-7} \frac{\sqrt{T^{3}\left(\frac{1}{M_{A}}+\frac{1}{M_{B}}\right)}}{P \sigma_{A B}^{2} \Omega_{D}}\left(\mathrm{~m}^{2} / \mathrm{s}\right)
$$

where $T$ : gas temperature $(\mathrm{K}) ; M_{A}$ : molecular weight of species $A(\mathrm{~kg} / \mathrm{kmol}) ; M_{B}:$ molecular weight of species $B(\mathrm{~kg} / \mathrm{kmol}) ; P$ : absolute pressure (atm); $\sigma_{A B}$ : collision diameter (LennardJones parameter, $\AA$ ); and $\Omega_{D}$ : collision integral. The binary diffusion coefficient for an airhelium mixture is calculated for both prototypic conditions $\left(T=850^{\circ} \mathrm{C}, P=1 \mathrm{~atm}\right)$ and scaleddown conditions $\left(T=750^{\circ} \mathrm{C}, P=1 \mathrm{~atm}\right)$ and are listed below:

$$
\begin{aligned}
& D_{\text {air-helium }}=6.41 \times 10^{-4} \mathrm{~m}^{2} / \mathrm{s} \quad\left(\text { at } 850^{\circ} \mathrm{C}, 1 \mathrm{~atm}\right) \\
& D_{\text {air-helium }}=5.49 \times 10^{-4} \mathrm{~m}^{2} / \mathrm{s} \quad\left(\text { at } 750^{\circ} \mathrm{C}, 1 \mathrm{~atm}\right)
\end{aligned}
$$

The diffusion length scales chosen for the diffusion time scale analysis are equal to the distances chosen for the DDAI time scale analysis. 
The calculated diffusion time scale is based on the amount of time it takes for the same mass of air that ingressed into the channel during the DDAI event to diffuse into the channel by molecular diffusion under the same geometric and thermal conditions. To calculate the molecular diffusion time scale, the transient diffusion problem in a semi-infinite medium is solved. The governing equation and the boundary conditions are given as:

$$
\left.\begin{array}{l}
\frac{\partial \rho_{a}}{\partial t}=D_{\text {air-helium }} \frac{\partial^{2} \rho_{a}}{\partial z^{2}}, 0<z<\infty, t>0 \\
\rho_{a}(z, t=0)=0,0<z<\infty \\
\rho_{a}(z=0, t)=\rho_{a, s}, t>0 \\
\rho_{a}(z \rightarrow \infty, t)=0, t>0
\end{array}\right\}
$$

where $\rho_{a}$ : air density as a function of axial position $(z)$ and time $(t)$ and $\rho_{a, s}$ : air density at the break. The solution of the partial differential equation prescribed in Eq. (22) is given as

$$
\frac{\rho_{a}(z, t)}{\rho_{a, s}}=1-\operatorname{erf}\left(\frac{z}{2 \sqrt{D_{\text {air-helium }}}}\right)
$$

where $\operatorname{erf}(\phi)=\frac{2}{\pi} \int_{0}^{\phi} e^{-t^{2}} \mathrm{~d} t$ is the error function. To calculate the time required for a certain mass of air, $m_{a}(t)$, to diffuse into the channel, the volume integral of Eq. (23) is calculated over the length of the channel as:

$$
m_{a}(t)=2 \rho_{a, s} A_{c} \sqrt{\frac{D_{\text {air-helium }} t}{\pi}}
$$

Solving Eq. (24) for $t$, the amount of time for a given mass of air, $m_{a}(t)$, to diffuse into the channel can be calculated. Under prototypic conditions, it takes $14,160 \mathrm{~s}$ for $7.11 \mathrm{~kg}$ of air to diffuse into the channel. Similarly, it takes $258 \mathrm{~s}$ for $0.014 \mathrm{~kg}$ of air to diffuse into the channel 
under the scaled-down condition. This means that the diffusion time scale, $\tau_{\text {diff }}$, is $14,160 \mathrm{~s}$ and $258 \mathrm{~s}$ for the prototypic and scaled-down case, respectively.

With the minimum DDAI time scale, $\tau_{D D}$, minimum thermal time constant, $\tau_{\text {thermal }}$, and minimum diffusion time scale, $\tau_{\text {Diff }}$, known, the minimum total time scale, $\tau_{\text {total }}$, can be calculated. The total time scale is calculated as:

$$
\frac{1}{\tau_{\text {total }}}=\frac{1}{\tau_{D D}}+\frac{1}{\tau_{\text {thermal }}}+\frac{1}{\tau_{\text {Diff }}} .
$$

Table 3 summarizes the air-ingress time scales. Under the prototype conditions, the hot plenum natural circulation time scale and the molecular diffusion time are both about 880 times greater than the DDAI time scale. Under the scaled-down conditions, the hot plenum natural circulation time scale and the molecular diffusion time scale are about 550 and 45 times greater, respectively, than the DDAI time scale. This shows that the minimum total time scale is dominated by the DDAI time scale.

\section{Table 3}

Summary of air-ingress phenomenon time scales

CFD studies of the VHTR air-ingress accident conducted by Oh et al. (2011) conclude that the “expected onset of natural circulation time estimated by 3D CFD analysis is approximately 100 $\mathrm{s}$, which is $50 \%$ of that of FLUENT $2 \mathrm{D}$ analysis results." The scaled-down test facility is a model of the VHTR hot exit plenum and, therefore, cannot simulate any flow phenomenology pertaining to the core region. This means that the prototypic time domain which is relevant to the scaled-down test facility ranges from $t=0-100 \mathrm{~s}$. Since the time scale analysis shows that the total time scale for the prototype geometry is $16.04 \mathrm{~s}$, this means that the prototypic time domain which is relevant to the scaled-down test facility is approximately equivalent to $t=0-6 \tau_{\text {total }}$. This corresponds to a scaled-down test facility time domain ranging from $\mathrm{t}=0-36.3 \mathrm{~s}$. 
Using ANSYS Fluent, computational experiments are performed similar to those found in Ham et al. (2012) to analyze the air-ingress time scale. The CFD calculation analyzes a double-ended guillotine break scenario on the scaled-down test facility. The test facility is comprised of two pressure vessels that are attached by a flange. The main test vessel is an ASME certified vessel, which is a scaled-down model of the VHTR hot duct-hot exit plenum system. For this computational experiment, the main test vessel is filled with only helium gas that is pressurized to $0.308 \mathrm{MPa}$. The initial temperature of the helium gas and the solid internals of the main test vessel is $700^{\circ} \mathrm{C}$. The second vessel is the so-called containment vessel, which is initially filled with only air in this computational experiment. Its initial pressure and temperature is $0.101 \mathrm{MPa}$ and $27^{\circ} \mathrm{C}$, respectively. The numerical models and settings used for the three-dimensional (3D) CFD analysis are summarized as follows:

- Solver

- Pressure-Based

- Double Precision

- Transient: $1^{\text {st }}$-Order Implicit

- Species Transport Model

- Mixture Material: Mixture Template

- Two Species: Air and Helium

- Density: Ideal Gas

- Heat Capacity: Mixing Law

- Thermal Conductivity: Ideal Gas Mixing Law

- Viscosity: Ideal Gas Mixing Law
- Discretization

- Gradient: Least Squares Cell Based

- Pressure-Velocity Coupling: PISO

- Density: $2^{\text {nd }}-$ Order Upwind

- Momentum: $2^{\text {nd }}$-Order Upwind

- Turbulent Kinetic Energy: $2^{\text {nd }}-$ Order Upwind

- Turbulent Dissipation Rate: $2^{\text {nd }}$-Order Upwind

- Species: $2^{\text {nd }}$-Order Upwind

- Energy: $2^{\text {nd }}$-Order Upwind

- Viscous Model

- Realizable: k- $\varepsilon$

National Institute of Science and Technology's (NIST) chemistry web book is used for the species properties in the form of a polynomial function. ANSYS Meshing tool is used to create the polyhedral mesh inside the test section of the pressure vessel. In this analysis, the Richardson extrapolation method is used to estimate the higher-order solutions and quantify the error range systematically. To perform the Richardson extrapolation, three systematic grids are utilized in 
the computational domain: a fine mesh with 125,909 cells, a medium mesh with 51,464 cells, and a coarse mesh with 20,120 cells. The results presented here are based on the medium mesh.

Fig. 9 is a series of air mass fraction contour plots of the vertical mid-plane of the hot duct-hot exit plenum system in the main test vessel. The series of plots shows the progression of the air current as it moves across the bottom of the hot exit plenum. The six subfigures are arranged from top to bottom and correspond to the following times after the double-ended guillotine pipe break: $0.6,1.1,1.85,3.1,4.1$, and 4.6 s. From this computational experiment, it can be seen that the time of travel for the air plume to reach the halfway point of the hot exit plenum is approximately $1.85 \mathrm{~s}$ after the pipe break and it makes contact with the back wall at approximately $4.1 \mathrm{~s}$ after the pipe break.

Fig. 9. Progression of air plume during a density-driven air ingress event in the test section at time: (a) $t=0.6 \mathrm{~s}$, (b) $t$ $=1.1 \mathrm{~s}$, (c) $t=1.85 \mathrm{~s}$, (d) $t=3.1 \mathrm{~s}$, (e) $t=4.1 \mathrm{~s}$, and (f) $t=4.6 \mathrm{~s}$ following the break initiation

For a more direct comparison to the DDAI time scale generated by the CFD analysis, a DDAI time scale based on the experimental gravity current speed shown in Eq. (17) is calculated for the same density ratio. The experimental DDAI time scale for a length $L_{D D}=0.425 \mathrm{~m}$ is $0.24 \mathrm{~s}$. This is less than time scale observed from the CFD analysis, which is $1.85 \mathrm{~s}$. It is expected that the time scale of each analysis will be different since the geometry of each analysis is different. The geometry from which Lowe's experimental data was collected is a rectangular channel. The geometry from the CFD analysis is a right circular cylinder with an internal triangular array of graphite rods. In the CFD analysis geometry there are additional pressure losses that are not found in Lowe's experimental geometry; namely, expansion losses and additional lateral flow resistance due to the triangular bare rod array. Since there are additional sources of pressure loss in the CFD analysis compared to the Lowe's experimental geometry and the driving force of each situation is similar, it is expected that the DDAI time scale of the CFD analysis should be 
greater than the DDAI time scale calculated from Lowe's experimental data. DDAI time scale calculations of both cases support this reasoning. Currently, there is no experimental data available in the literature to validate the CFD analysis with its unique, hot exit plenum geometry. This demonstrates a need to obtain experimental data on a scaled-down hot exit plenum geometry to validate the actual time scale. With only lock exchange experimental data on a rectangular channel available, a complete DDAI time scale agreement with the current CFD analysis is not possible. However, an order-of-magnitude time scale similarity can show that the basic DDAI phenomenology is preserved despite the experiments being performed on two different geometries.

\subsection{Transient Depressurization Analysis of the Reactor Vessel}

In the event of a LOCA of a GT-MHR, the pressure boundary of the reactor is compromised, leading to a depressurization in which the helium in the reactor system empties into the enclosure that houses the reactor vessel. In this analysis, helium is released from the reactor vessel through a break in the cross vessel of the reactor. The analysis that follows shows that the depressurization is a rapid process whose time scale is much shorter than the overall time scale of the air-ingress accident. Following the depressurization, the analysis also shows that the helium temperature inside the vessel recovers to its initial temperature in a time which is on the same order of magnitude as the air-ingress accident time scale for both types of geometry.

In the present analysis, a simple model for describing the depressurization process of a heliumfilled reactor vessel with internal structures is employed. It uses a lumped capacitance model to reveal the integral changes taking place during the depressurization (Xia et al., 1993). This simplified model assumes constant thermo-physical properties except for the helium density. A constant heat transfer coefficient between the solid structures and the helium is assumed for each 
case. The heat transfer coefficient is parametrically varied as shown in Figs. 10 and 11. The energy conservation equations for the helium and the internal solid structures are given as:

$$
\begin{gathered}
\frac{\mathrm{d}\left(m_{h e}(t) c_{v, h e} T_{h e}(t)\right)}{\mathrm{d} t}=h A_{s}\left(T_{w}(t)-T_{h e}(t)\right)-\dot{m}_{h e}(t) c_{p, h e} T_{h e}(t) \\
\rho_{w} V_{w} c_{p, w} \frac{\mathrm{d} T_{w}(t)}{\mathrm{d} t}=0.066 P_{0} t^{-0.2}-h A_{s}\left(T_{w}(t)-T_{h e}(t)\right)
\end{gathered}
$$

where $m_{h e}(t)$ : helium mass in the vessel at time $t, c_{v, h e}$ : helium specific heat at constant volume, $T_{h e}(t)$ : helium bulk temperature in the vessel at time $t, h$ : average convective heat transfer coefficient from the vessel solid internals to the helium inside the vessel, $A_{s}:$ surface area of vessel internals, $T_{w}(t)$ : average temperature of vessel solid internals at time $t, \dot{m}_{h e}(t)$ : helium exit mass flow rate at time $t, c_{p, h e}$ : helium specific heat capacity at constant pressure, $\rho_{w}$ : average density of vessel solid internals, $V_{w}$ : volume of vessel solid internals, $c_{p, w}$ : average specific heat capacity at constant pressure of vessel solid internals, and $P_{o}$ : steady-state operating power level.

Fig. 10. Helium temperature versus time during depressurization of the prototypic vessel

Fig. 11. Helium temperature versus time during depressurization of the scaled-down facility The mass balance equation is given as

$$
m_{h e}(t)=m_{o}-\int \dot{m}_{h e}(t) \mathrm{d} t \approx m_{o}-\dot{m}_{h e} \delta t
$$

where $m_{o}$ : initial mass of helium in the vessel. From the momentum equation for a steady incompressible flow, the depressurization helium velocity can be calculated. The velocity expression takes into account the sudden contraction from the vessel to the hot duct and the friction along the duct. The helium velocity, $v(t)$, out of the hot duct at time $t$ is given as: 


$$
v(t)=\sqrt{\frac{P(t)-P_{a m b}}{\rho_{\text {avg }}\left(\frac{\alpha}{2}+\frac{1}{2}\left(K_{c}+\frac{f l}{d_{h}}\right)\right)}}
$$

where $P(t)$ : helium global pressure in the vessel at time $t, P_{a m b}:$ helium-air gas mixture pressure in the vessel containment, $\rho_{\text {avg }}$ : average helium density in the hot duct, $\alpha$ : kinetic energy coefficient, $K_{c}$ : pressure loss coefficient for a sudden contraction, $f$ : Darcy friction factor, $l$ : hot duct length, and $d_{h}$ : hydraulic diameter of hot duct. The kinetic energy coefficient is taken to be the value that corresponds to a flat velocity profile. This is a fair approximation since the flow through the duct is turbulent for most of the depressurization transient. The duration of the depressurization is very short. Under the prototype condition, the pressure in the vessel drops to near the atmospheric pressure in $0.4 \mathrm{~s}$ for a double-ended guillotine break (DEGB). In the scaleddown geometry with an initial helium pressure of 30 psig in the vessel, the duration of a DEGB depressurization is 0.01 s. Figs. 10 and 11 show the helium temperature during a depressurization versus time for different heat transfer coefficients for the prototypic and scaleddown geometries, respectively.

In the prototype geometry, the duration of the depressurization is two orders of magnitude smaller than the density-driven air ingress time scale and five orders of magnitude smaller than the hot plenum natural circulation and diffusion time scale. Similarly, in the scaled-down geometry, the duration of the depressurization is two orders of magnitude smaller than the density-driven air ingress, five orders of magnitude smaller than the hot plenum natural circulation time scale, and four orders of magnitude smaller than the diffusion time scale. This means that the duration of the depressurization is two orders of magnitude smaller than the total 
time scale, $\tau_{\text {total }}$, for both the prototypic and scaled-down geometries. Therefore, the duration of the depressurization is negligible when compared to the total time scale of the air-ingress accident in the scaled-down test section.

Comparing Figs. 10 and 11, it can be seen that there is a significant difference between the helium temperature in the prototype and the scaled-down geometry. This is largely due to the different initial vessel pressure in each case. During the release of helium, the temperature of the fluid initially decreases with respect to time due to the expansion of the helium inside the vessel. Since there is a higher initial helium pressure in the prototypic vessel, this causes a larger temperature decrease than in the test facility vessel. As the pressure of the helium inside the vessel approaches the atmospheric pressure, the heat transferred from the reactor vessel solid internals and vessel wall to the fluid cause the temperature of the helium to increase. This temperature increase is observed in both cases. The recovery time of the helium temperature varies with the heat transfer coefficient. For the three heat transfer coefficients used in this analysis, the recovery time of the vessel helium temperature varies from approximately 1 to 15 seconds. In the median case, the heat transfer coefficient from the vessel internals and wall to the fluid is $10 \mathrm{~W} /\left(\mathrm{m}^{2}-\mathrm{K}\right)$. The recovery time for this case is about three seconds for both types of geometry. This recovery time is on the same order of magnitude as the overall time scale of the air-ingress phenomenon for both types of geometry.

\subsection{Hydraulic Similarity of the Test Facility}

Utilizing the geometric scaling analysis, a model is created to find the best support column diameter and pitch for the test facility to mimic the loop pressure loss distribution of a hot ducthot exit plenum system as discussed in Arcilesi et al. (2012). This is accomplished by calculating the pressure loss distribution and the Froude number in the prototype system and then modifying 
the pitch and diameter of the support columns until the Froude number in the experimental system matches that of the prototype.

A 1D approach is used for this model, since the flow can be considered 1D if the entire domain is divided into five sections as illustrated in Fig. 12. The model assumes that the test facility's height, support column height, hot duct diameter and plenum diameter are a $1 / 8$ th scale of the prototypic dimensions. Furthermore, the hot duct length is assumed to be $0.1 \mathrm{~m}$. In the event of a hot duct break at the edge of the power conversion unit, the scaled-down length is $0.3575 \mathrm{~m}$ (which is equal to $1 / 8$ of $2.86 \mathrm{~m}$ ). The hot duct length has been shortened to $28 \%$ of the actual scaled-down length because the frictional pressure loss in the duct at the actual scaled-down length $(0.3575 \mathrm{~m})$ dominated the overall pressure loss. In this situation, it would have been very difficult to design a test facility that could mimic the pressure loss distribution through the prototypic system. Other dimensions such as the support column diameter and pitch are scaled by different factors to be determined in the current analysis.

Fig. 12. Hot duct-hot exit plenum system with control volumes outlined

The first segment shown in Fig. 12 is the bottom half of the hot duct. Its cross-sectional area is a semicircle. The second segment is the bottom half of the hot exit plenum whose constant width is equal to the vessel diameter $(6.8 \mathrm{~m}$ in the prototype geometry and $0.85 \mathrm{~m}$ in the scaled-down geometry). This means that for the purpose of this analysis the shape of the second segment is a right rectangular prism or right cuboid - not a right circular cylinder, which is the prototypic geometry. This type of geometry is prescribed for the analysis because the pressure loss correlation for lateral flow resistance across the bare rod arrays is dependent on the number of tube rows in the direction of flow (Todreas and Kazimi, 1993). Therefore, it gives a value to the pressure loss for a rectangular array of tubes. This type of correlation and model distorts the 
actual geometry. However, since preserving the Froude number, the resistance number, and the overall loop pressure loss distribution between the two geometries is the primary concern, the overestimate in the pressure loss and geometry distortion is neglected due to the consistent treatment of the analysis for both geometry types. The third segment is the gas rising from the bottom to the top of the hot exit plenum. In this analysis, the flow cross-sectional area of this segment is circular-shaped as prescribed in the prototypic geometry. The fourth segment is the top half of the hot exit plenum whose constant width is again equal to the vessel diameter as explained for the second segment. The fifth segment is the top half of the hot duct. Hence, its flow cross-sectional area is a semicircle. In Table 4, the types of pressure loss calculated for each section are listed. The expansion and contraction pressure loss correlations are taken from Idelchik (1986).

\section{Table 4}

Types of pressure loss considered for each section of the test facility

For each case, segments (1) and (2) are at the cold fluid temperature. Segments (4) and (5) are at the high temperature, which is $850^{\circ} \mathrm{C}$ in the prototypic system and $750^{\circ} \mathrm{C}$ in the scaled-down system. $850^{\circ} \mathrm{C}$ is chosen for the prototypic system because it is the core outlet temperature during normal operation of the GT-MHR (General Atomics, 1996). $750^{\circ} \mathrm{C}$ is chosen as the high temperature for the scaled-down system since this temperature corresponds to the overall rating of the main test vessel. Segment (3) is at the average temperature of the hot and cold temperatures. The pressure for all five segments is approximated as the atmospheric pressure. Since there is a temperature difference within the system, there exists a density difference or a driving force, $\Delta P_{d}$, for natural circulation. Mathematically, the driving force is expressed as

$$
\Delta P_{d}=\left(\rho_{c}-\rho_{h}\right) g h
$$


where $\rho_{c}$ and $\rho_{h}$ are the densities for the cold and hot fluids, respectively; $g$ is the acceleration of gravity and $h$ is the height of the hot plenum. Therefore, for a given case, there is a set driving force for natural circulation in the system.

Having established the natural circulation driving force for the system, the velocity is iterated until the resistance pressure drop, $\Delta P_{r e s}$, is essentially equal to the driving force, $\Delta P_{d}$, i.e., $\left|\Delta P_{d}-\Delta P_{r e s}\right|<10^{-6}$. Mathematically, the resistance pressure drop is expressed as

$$
\Delta P_{r e s}=\frac{1}{2} \sum_{i=1}^{5} K_{T, i} \rho_{i} v_{i}^{2}
$$

where $K_{T, i}$ is the total loss coefficient for the $i^{\text {th }}$ segment; $\rho_{i}$ and $v_{i}$ are the fluid density and the fluid velocity in the $i^{\text {th }}$ segment, respectively. It should be noted that the model assumes that the amount of mass within the entire system does not change with time. Therefore, the mass flow rate remains constant from segment to segment. Using this approximation, along with the density and flow area of each segment, the velocity for a given control volume can be found.

Once this procedure has been followed for the prototypical geometry of a given set of temperatures, there is a unique Froude number that is recorded. Now, with the scaled-down geometry, the velocity is adjusted to preserve the Froude number of a given case. This means that the velocity is reduced by a factor of $\sqrt{8}$ in order to preserve the Froude number. Since an adjustment of both the fluid velocity as well as the geometry has taken place, the driving force, in general, is no longer equal to the resistance pressure drop. Therefore, in order to equate the driving pressure to the resistance pressure drop, the support column diameter and pitch are reduced by the same scaling factor until equivalence is achieved. 
Table 5

Species composition and temperature for each segment for single-species calculations

These simulations are completed for nine different cases. Cases (1) - (6), given in Table 5, are single species simulations (either Air or He). Cases (7) - (9) are mixed species simulations as shown in Table 6. To calculate the thermo-physical properties of the air-helium mixtures, the relations from Banerjee and Andrews (2007) are utilized. All simulations are performed at the atmospheric pressure for all the control volumes.

Table 6

Species composition and temperatures for each segment for mixed-species calculations

By maintaining the Froude number similarity and adjusting the support column pitch and diameter to balance the natural circulation driving force with the pressure drop, a set of support column (SC) pitches and diameters is collected. Each case has a unique pitch and diameter that ensures that these conditions are satisfied. These values are tabulated in Table 7 along with the arithmetic average of the nine values.

Table 7

Resultant support column pitches and diameters

From the tabulated values, the support column pitch and diameter for the scaled down test facility to ensure a hydraulic similarity is $8.8 \mathrm{~cm}$ and $5.2 \mathrm{~cm}$, respectively. This average does not include the values from case 3 . This is justified since it is not physically realizable to have $100 \%$ helium at a low temperature of $500^{\circ} \mathrm{C}$ and at a high temperature of $850^{\circ} \mathrm{C}$ circulating through the hot duct-hot exit plenum system within the scope of this accident. It should be noted that the pitch and diameter are scaled by the same factor. Hence, the pitch-to-diameter ratio in the scaleddown test facility is equal to the pitch-to-diameter ratio in the prototype. 
From the geometric scaling analysis, another key non-dimensional number is the resistance number - Eq. (16). For the nine cases prescribed in Table 5 and 6 , the ratio $(R)$ of the resistance number for the scaled-down model $(m)$ to the prototypic design $(p)$ is given in Table 8 . It can be observed from Table 8 that in most cases the similarity ratio is nearly one. The average value is 1.007. This is almost perfect for the similarity ratio being equal to unity. Mathematically, this is expressed as

$$
R=\frac{\left(\Pi_{F}\right)_{m}}{\left(\Pi_{F}\right)_{p}} .
$$

\section{Table 8}

Resistance number similarity ratio for each case

The similarity ratio $(R)$ is a metric that compares the non-dimensional friction number of the scaled-down system to the non-dimensional friction number of the prototypic system. While it is necessary to maintain the similarity ratio near unity to preserve hydraulic similarity between the two geometries, this type of metric is not a sufficient condition to show that the distribution of the loop pressure loss of both geometries is equivalent. To demonstrate the level of pressure loss equivalency segment by segment, Table 9 lists the percentage of the total pressure loss for a given segment, case, and geometry type. The segment numbers correspond to the segments illustrated in Fig. 12. The case numbers in Table 9 are identical to the case numbers and their corresponding thermal and species conditions listed in Table 5 and 6 . The geometry types follow from the physical description and dimensions given in Section 2.1 and Table 1.

\section{Table 9}

Loop pressure loss distribution of prototypic and scaled-down geometries 
Overall, the similarity of the pressure loss distribution percentages is good. As shown near the bottom of Table 9, the average difference between the prototypic and the scaled-down geometry types for each segment is given as well as the largest and smallest differences. The average difference, largest difference, and smallest difference exclude case 3 . The average difference of each segment is reasonable, which suggests good hydraulic similarity between the two geometry types.

Utilizing the pitch and diameter calculated from the hydraulic similarity analysis and the scaleddown dimensions of the hot exit plenum, all the dimensions of the hot duct-hot exit plenum system are set. A CFD simulation of the scaled-down geometry is performed to investigate the ingress of air into the scaled-down hot exit plenum. The hexagonal orientation of the support columns in the scaled-down hot exit plenum is the same orientation of the support columns in the prototypic hot exit plenum. In this computational experiment, the main test vessel is filled with helium that is pressurized to $0.308 \mathrm{MPa}$. The initial temperature of the helium gas and the solid internals of the test section is $700^{\circ} \mathrm{C}$. The second vessel, i.e., the so-called containment vessel, is initially filled with air to an initial pressure and temperature of $0.101 \mathrm{MPa}$ and $27^{\circ} \mathrm{C}$, respectively. The numerical models and settings for the 3D CFD analysis are identical to those given in the CFD analysis in Section 3.1.

Fig. 13 shows a series of air mass fraction contour plots of the overhead view of the hot exit plenum. These air mass contour plots are taken at the bottom of the test section - directly on top of the bottom plate at a height of $z=0$. In these plots, the hot duct is not shown but it can be deduced that the duct opening is located at the top of each contour plot. The six plots represent the air mass fraction distribution at the bottom of the test section at six given times: $t=0.6,1.1$, $1.85,3.1,4.1$, and $4.6 \mathrm{~s}$. 
As the air plume travels along the bottom of the test section, the center region of the plume is in front for the majority of the plume's progression to the back of the test section. However, when the plume approaches the back of the test section, the peripheral region of the plume accelerates and arrives at the back of the test section at approximately the same time as the center region of the plume. This predicted phenomenon is due to the increased pressure loss of the fluid as it passes through the support columns as opposed to the fluid whose flowpath is around the periphery of the test section, not through the support columns. This CFD analysis provides insight for the placement of the instrumentation in the scaled-down test facility. Fig. 14 shows the top view of the bottom plate with the instrumentation ports added. Many of the instrumentation ports are located along the center of the plate to track the progression of the initial plume. There are five thermocouple ports, three oxygen $\left(\mathrm{O}_{2}\right)$ sensor ports, and two pressure ports along the center to measure fluid temperature, oxygen concentration, and fluid pressure. In addition, there are thermcouple ports and pressure sensor ports that span out from the center to measure temperature and pressure of the width of the initial plume as illustrated in Figs. 13 and 14. In the experiments, temperature and oxygen concentration measurements will be used to follow the progression of the initial air ingress plume and to validate the data from this and many other CFD simulations.

Fig. 13. Overhead view of the propagation of the air plume at the bottom of the test section at time: (a) $t=0.6 \mathrm{~s}$, (b) $t=1.1 \mathrm{~s}$, (c) $t=1.85 \mathrm{~s}$, (d) $t=3.1 \mathrm{~s}$, (e) $t=4.1 \mathrm{~s}$, and (f) $t=4.6 \mathrm{~s}$ following the break initiation

Fig. 14. Top view of bottom plate with instrumentation ports to measure initial air ingress plume

\subsection{Heat Transfer Characterization of the Hot Plenum}

Understanding the heat transfer performance of the system is pivotal in characterizing how quickly the air ingress phenomena will transition from the first stage of density-driven air ingress 
to the second stage of hot plenum natural circulation. To estimate the time scale of this transition, it's essential to understand the primary heat source during the course of the accident: the graphite support columns located in the hot exit plenum. The graphite support columns receive most of their heat via heat conduction from the reactor core above them.

Using a 1D, steady-state fin analysis, a temperature profile is derived for a single IG-110 graphite support column for three limiting cases. In case 1, Dirichlet boundary conditions are prescribed where the temperatures at the top and bottom surface of the column are given as $T_{\text {top }}=850^{\circ} \mathrm{C}$ and $T_{\text {bottom }}=490^{\circ} \mathrm{C}$ as illustrated in Fig. 1(b). These two temperatures are chosen because they are the outlet and inlet temperatures of the core during normal operation (General Atomics, 1996). In case 2, mixed boundary conditions are employed with $T_{\text {top }}=850^{\circ} \mathrm{C}$ and an adiabatic condition at the graphite column bottom, i.e., $q_{\text {bottom }}^{\prime \prime}=0$, where $q_{\text {bottom }}^{\prime \prime}$ is the heat flux at the bottom of the support column. In case 3 , the wall temperature for the entire column is assumed to be constant; that is, $T(z)=850^{\circ} \mathrm{C}$ for $z \in\left[0, H_{s c}\right]$, where $H_{s c}$ is the support column height and $z$ is the variable describing the vertical position of the column. The top of the column is at $z=0$ and the bottom of the column is at $z=H_{s c}$. For case 1 , the excess temperature distribution is described by

$$
\theta_{1}(z)=\frac{\theta_{\text {bottom }} \sinh (m z)+\theta_{t o p} \sinh \left[m\left(H_{s c}-z\right)\right]}{\sinh \left(m H_{s c}\right)}
$$

where $\theta(z) \equiv T(z)-T_{\infty}, \theta_{\text {bottom }} \equiv T_{\text {bottom }}-T_{\infty}, \theta_{\text {top }} \equiv T_{\text {top }}-T_{\infty}, m^{2} \equiv \frac{h P_{w}}{k A_{s c}}:$ support column/graphite cylinder inverse characteristic length, $h$ : convective heat transfer coefficient from the column 
surface to the surrounding gases, $P_{w}$ : wetted perimeter of the support columns, $k$ : support column thermal conductivity, and $A_{s c}$ : support column cross-sectional area.

For case 2, the excess temperature distribution is described by the following equation:

$$
\theta_{2}(z)=\theta_{t o p} \frac{\cosh \left[m\left(H_{s c}-z\right)\right]}{\cosh \left(m H_{s c}\right)}
$$

By integrating $\theta(z)$ over the interval from 0 to $H_{s c}$ and dividing by $H_{s c}$, the average excess temperature, $\bar{\theta}$, is found. For cases 1 and 2, the average excess temperature are described by

$$
\bar{\theta}_{1}=\frac{\theta_{t o p}}{m H_{s c} \sinh \left(m H_{s c}\right)}\left[\left(\frac{\theta_{b o t t o m}}{\theta_{t o p}}+1\right)\left(\cosh \left(m H_{s c}\right)-1\right)\right]
$$

and

$$
\bar{\theta}_{2}=\frac{\theta_{t o p}}{m H_{s c}} \tanh \left(m H_{s c}\right)
$$

For case 3, the average excess temperature is given as:

$$
\overline{\theta_{3}}=\theta(z) \equiv T(z)-T_{\infty} .
$$

Using the three different cases, a parametric study is performed to calculate the natural convection heat transfer coefficient from the support column to the surrounding gas. The average value of the three cases is calculated. They are calculated for different far-field gas temperatures (from $20-500^{\circ} \mathrm{C}$ ) and for different air/helium species compositions (from $0-100 \%$ air mole fraction in $10 \%$ mole fraction increments). The thermo-physical properties of the gas mixture are calculated based on the film temperature, which is defined as the arithmetic mean of the average support column temperature and the far-field gas temperature. The helium thermo-physical properties are taken from correlations found in Petersen (1970). The correlations for the air density, air viscosity, and specific heat of air are taken from Zografos et al. (1987) and the 
correlation for thermal conductivity of air is taken from Latini et al. (1996). The Nusselt number is calculated based on the Rayleigh number in accordance with the following correlations for natural convection (Holman, 1976)

$$
N u=\left\{\begin{array}{l}
0.59(R a)^{1 / 4}, 10^{4}<R a<10^{9} \\
0.10(R a)^{1 / 3}, 10^{9}<R a<10^{13}
\end{array}\right.
$$

The average heat transfer coefficient due to natural convection is calculated from the Nusselt number and average support column wall temperature is recalculated from either Eqs. (35), (36), or (37). This process is repeated until convergence is achieved.

These calculations are performed for prototypic dimensions at prototypic temperatures; that is, the boundary conditions are the same as outlined in cases 1, 2, and 3. Fig. 15 shows the results of the prototypic case. Similar calculations are repeated for the scaled-down dimensions at a high temperature of $750^{\circ} \mathrm{C}$. In these calculations, the boundary conditions are the same as outlined in cases 1,2 , and 3 except that $T_{\text {top }}=750^{\circ} \mathrm{C}$ for cases 1 and 2 and $T(z)=750^{\circ} \mathrm{C}$ for case 3 . The results of these calculations are shown in Fig. 16.

Fig. 15. Average heat transfer coefficient vs. air mole fraction for the prototype geometry

Fig. 16. Average heat transfer coefficient vs. air mole fraction for the scaled-down geometry

The heat transfer coefficient varies from about $3-12 \mathrm{~W} /\left(\mathrm{m}^{2}-\mathrm{K}\right)$ for the prototype geometry and 5$15 \mathrm{~W} /\left(\mathrm{m}^{2}-\mathrm{K}\right)$ for the scaled-down geometry. Despite imposing three different types of boundary conditions and varying both the far-field gas temperature and the gas species composition over a wide range of values, the heat transfer coefficient remains in a sufficiently small interval such that the natural circulation phenomenology does not vary significantly for both the prototype and scaled-down geometries. In addition, the ranges of the heat transfer coefficients for the prototype 
and scaled-down geometries are very similar; therefore, there is considerable overlap of the heat transfer coefficients between the two geometry types. This means the basic natural circulation phenomenology is preserved, which ensures that a high degree of heat transfer similarity is maintained during the experiments.

\subsection{Power Scaling Analysis for Scaled-down Test Facility}

In the prototypic system, the graphite columns receive heat primarily due to heat conduction from the reactor core above them. In the scaled-down test facility, however, the core region is not included. Therefore, electric heaters will be used and placed inside graphite rod shells to simulate heat conduction from the reactor core. To establish the heater power of this shell/heater system in the scaled-down test facility to preserve the natural circulation phenomenology, a MATLAB code is written to calculate the $2 \mathrm{D}(r, z)$ temperature profiles for (A) a prototypic support column, (B) a scaled-down graphite cylinder, and (C) a scaled-down shell/heater system. This control volume analysis is similar to the one performed in Arcilesi et al. (2013). A high temperature $\left(750^{\circ} \mathrm{C}\right)$ on the outer surface of the shell wall needs to be achieved without exceeding the maximum heater sheath temperature $\left(1120^{\circ} \mathrm{C}\right)$ of a Watlow ${ }^{\circledR}$ MULTICELL ${ }^{\mathrm{TM}}$ insertion heater. A schematic of this design is shown in Fig. 17. A 1D, steady-state calculation shows that an outer graphite column wall temperature of $750^{\circ} \mathrm{C}$ can be achieved while the heater is exerting $1.0 \mathrm{~kW}$. Under these conditions, the calculation also shows that the surface temperature of the heater is approximately $900^{\circ} \mathrm{C}$, which is well below the aforementioned maximum heater sheath temperature.

Fig. 17. (a) Overhead view of case (C) and (b) Side cut view of scaled-down shell/heater system of case (C) The current analysis takes into account the heat conducted at the top and the bottom boundaries of the support column. Mathematically, this is demonstrated by imposing fixed temperature 
(Dirichlet) boundary conditions at the top and bottom boundaries of the support column. The right boundary condition is a Newton cooling boundary condition for all three cases. For cases (A) and (B), the left boundary condition is a symmetry boundary condition or no-heat-flux boundary condition. In case $(\mathrm{C})$, the left boundary condition imposes the heat flux of the insertion heater at the inside surface of the graphite shell wall. The boundary conditions for cases (A) - (C) are summarized in Table 10. The governing equation is a $2 \mathrm{D}$ heat diffusion transient equation for cylindrical coordinates as:

$$
\rho c_{p} \frac{\partial T}{\partial t}=\frac{1}{r} \frac{\partial}{\partial r}\left(k r \frac{\partial T}{\partial r}\right)+\frac{\partial}{\partial z}\left(k \frac{\partial T}{\partial z}\right) ; r_{1} \leq r \leq r_{2} ; t \geq 0
$$

where $r_{1}$ and $r_{2}$ are the inner and outer radius of the graphite cylinder/shell, respectively. In cases (A) and (B), $r_{1}=0$. In case (C), $r_{1}=0.0127 \mathrm{~m}$. In case (A), $r_{2}=0.106 \mathrm{~m}$, which is the radius of the prototypic support column. In cases (B) and (C), $r_{2}=0.026 \mathrm{~m}$, which is the radius of the scaled-down graphite cylinder.

\section{Table 10}

Boundary conditions for a 2D temperature profile analysis

The initial condition that is imposed in the analysis is $750^{\circ} \mathrm{C}$ everywhere on the graphite cylinder/shell. The average heat transfer coefficients used in this calculation are the largest values calculated from Figs. 15 and 16 in the 1D fin analysis from Section 3.4., i.e., 12.41 $\mathrm{W} /\left(\mathrm{m}^{2}-\mathrm{K}\right)$ for case (A) and $15.44 \mathrm{~W} /\left(\mathrm{m}^{2}-\mathrm{K}\right)$ for cases $(B)$ and $(\mathrm{C}) .20^{\circ} \mathrm{C}$ is used as the far-field gas temperature. Under these conditions, it allows for the maximum possible heat removal from a support column. Therefore, if the temperature profile of the support column or shell/heater system is relatively flat under these conditions, it is certain that the lumped capacitance approximation is valid under all other expected conditions during a VHTR air-ingress accident. 
Furthermore, it determines the maximum required heater power to maintain the temperature profile similarity in the shell/heater system. The governing equation is discretized using a finite volume discretization and an explicit time-marching scheme.

Using this method, temperature contour plots have been generated for cases (A) - (C) as shown in Table 10 at time $t=6 \tau_{\text {total }}$, where the total time scale, $\tau_{\text {total }}$, is defined in Eq. (25). To simplify the comparison of the temperature profiles, the radial and axial direction (or $r$ - and $z$-axis, respectively) have been normalized with respect to the case's column geometry. In this analysis, graphite density is taken to be a constant value of $1,770 \mathrm{~kg} / \mathrm{m}^{3}$. The thermal conductivity and specific heat capacity vary with temperature and correlations for the IG-110 graphite were derived from data in the available literature (Maruyama et al., 1995) as:

$$
\begin{gathered}
k(T)=3 \times 10^{8} T^{3}-1 \times 10^{-5} T^{2}-0.0612 T+125.56[\mathrm{~W} /(\mathrm{m}-\mathrm{K})] \\
c_{p}(T)=9 \times 10^{-7} T^{3}-0.0027 T^{2}+3.0203 T+643.24[\mathrm{~J} /(\mathrm{kg}-\mathrm{K})]
\end{gathered}
$$

where $T$ is in ${ }^{\circ} \mathrm{C}$. Eqs. (40) and (41) are valid for a temperature range of $20-800^{\circ} \mathrm{C}$.

Figs. 18 to 20 are the $2 \mathrm{D}$ temperature contour plots at $t=6 \tau_{\text {total }}$ of a prototypic support column, scaled-down graphite cylinder, and the scaled-down shell/heater system at $\dot{Q}=125 \mathrm{~W}$, respectively. It can be observed that the temperature profiles are flat. There is, at most, a temperature difference of $10^{\circ} \mathrm{C}$ where the absolute temperature is around $750^{\circ} \mathrm{C}$. This reaffirms the lumped capacitance approximation method of the support columns. Secondly, this analysis shows that the operational power of the insertion heater during the course of an experiment should be set around $125 \mathrm{~W}$ as shown in Fig. 20. At this heater power, the surface temperature profile of the shell/heater system is nearly identical to the surface temperature profiles of the prototypic support column and scaled-down graphite cylinder. Also, the radial temperature gradients of the graphite cylinders for all three geometry types are similar when the heater of the 
shell/heater system is exerting $125 \mathrm{~W}$. For these two reasons, a heater power of $125 \mathrm{~W}$ is chosen as the operational heater power for the proposed set of high-temperature experiments. This will assist in preserving the similarity of the natural circulation phenomenology during the air-ingress transient.

Fig 18. Temperature contour plot of prototypic support column (Case A) at $t=6 \tau_{\text {total }}$

Fig. 19. Temperature contour plot of scaled-down test facility graphite cylinder (Case B) at $t=6 \tau_{\text {total }}$

Fig. 20. Temperature contour plot of scaled-down test facility shell/heater system for $125 \mathrm{~W}$ (Case C) at $t=6 \tau_{\text {total }}$

\subsection{Design Analysis of Containment}

Following a depressurization of the reactor pressure vessel, hot helium from the reactor vessel mixes in the vessel containment with relatively cool air. The mixing process creates a mixed species temperature and a mixed species concentration, which have a significant effect on the following stages of an air-ingress accident especially the density-driven stratified flow. In this analysis, calculations are performed to find the free volume of the scaled-down containment vessel based on the initial pressure of the scaled-down pressure vessel so that the prototypic airto-helium mole ratio is maintained. By establishing the free volume of the scaled-down containment vessel, parameters of the scaled-down test facility can be adjusted so that the final mixing temperature and the mixed species concentration in the prototypic case can be preserved in the scaled-down experiments.

Utilizing the prototypic geometry and normal operating conditions of the GT-MHR, the mole ratio of air in the containment to helium in the pressure vessel is 5.13 . In order to maintain this mole ratio, the containment volume of the scaled-down geometry is calculated for different initial vessel pressures. Table 11 lists the parameters of the calculation.

\section{Table 11}

Parameters for containment vessel free volume calculation 
In this calculation, the ideal gas law is used to calculate the free volume of the scaled-down containment so that the air-to-helium mole ratio is the same as that found in the prototypic case. The results are summarized in Table 12 that gives the required containment vessel free volume for different initial vessel pressures. Based on the pressure limitations of the scaled-down test facility's oxygen sensors, which is $0.308 \mathrm{MPa}$, a scaled-down containment free volume is $1 \mathrm{~m}^{3}$ despite the pressure vessel being designed to withstand $0.343 \mathrm{MPa}$ at the design temperature.

\section{Table 12}

Scaled-down containment free volume for different initial vessel pressures

In addition to the previous analysis, the mean temperature of the mixture in the pressure vesselcontainment vessel system is calculated by using the first law of thermodynamics. This analysis is performed to give the final temperature of the air-helium mixture at the end of the helium depressurization. This mean temperature occurs theoretically after the contents are well-mixed. It is also assumed that no heat is gained or lost to or from the containment and that no work is done by the control volume since the control volume is a rigid volume. Therefore, the total internal energy of the system at the final and initial stages is the same. The final temperature of the system can be approximated as:

$$
T_{f}=\frac{\left(m_{h e} c_{v_{i}, h e} T_{h e, i}+m_{a} c_{v_{i}, a} T_{a, i}\right)}{\left(m_{h e} c_{v_{f}, h e}+m_{a} c_{v_{f}, a}\right)},
$$

where $m_{a}$ and $m_{h e}$ are the mass of the air and helium in this closed system analysis, respectively. $T_{f}, T_{h e, i}$, and $T_{a, i}$ are the final temperature of the air-helium gas mixture, initial helium temperature, and the initial air temperature, respectively. Since the specific heat capacity of air is a function of temperature, Eq. (42) is solved iteratively. Using the initial conditions listed in Table 13, the final air-helium gas mixture temperature in the prototypic case is $382.6 \mathrm{~K}$. Using 
the ideal gas law, the final air-helium gas mixture pressure in the prototypic pressure vessel and containment is $0.154 \mathrm{MPa}$. Performing the same analysis for the scaled-down geometry, the final air-helium gas mixture temperature and pressure are $369.8 \mathrm{~K}$ and $0.123 \mathrm{MPa}$, respectively. In reality, the calculated final temperature is not an exact representation of the true final gas mixture temperature since the helium left in the reactor pressure vessel will be at a higher temperature due to heating from the reactor pressure vessel's in-core structures. This final temperature, however, does serve as a suitable approximation. It is important to note that the difference of the final mixture temperature between the two cases is minimal - about a $3.5 \%$ difference. Additionally, the air-to-helium mole ratio of the prototypic case is 5.13, while the air-to-helium mole ratio of the scaled-down case is 5.34 . This accounts for a $4.2 \%$ difference between the two cases. The small differences between the final mixture temperature and the air-to-helium mole ratio of the prototypic and scaled-down case suggest that the overall phenomenology of the density-driven stratified flow is maintained between the two cases.

\section{Table 13}

Initial conditions for final mixture temperature analysis for the prototype and scaled-down geometry

In the GT-MHR containment, the venting system allows for gas to escape when it exceeds 1 psid across the containment wall. Therefore, the global pressure within the containment is maintained at or very near atmospheric pressure in the prototypic design (General Atomics, 1996). Since the final pressure in the first law analysis is above the atmospheric pressure, a transient control volume analysis is performed. By assuming that only air escapes from the containment at its initial temperature, the final gas mixture temperature can be approximated as follows:

$$
T_{f}=\frac{\left(-m_{e} c_{p, a} T_{a, i}+m_{h e} c_{v_{i}, h e} T_{h e, i}+m_{a, i} c_{v_{i}, a} T_{a, i}\right)}{\left(m_{h e} c_{v_{f}, h e}+m_{a, f} c_{v_{f}, a}\right)}
$$


where $m_{e}=m_{a, i}-m_{a, f}$ is the difference between, $m_{a, i}$, the initial mass of air in the containment vessel and, $m_{a, f}$, the final mass of air in the containment vessel. $T_{a, i}$ and $c_{p, a}$ are the initial temperature and the specific heat capacity at constant pressure of the air in the containment vessel, respectively. Iterating over Eq. (43) and using the ideal gas law, a final temperature can be calculated. All final pressures are the atmospheric pressure. A summary of the results can be found in Table 14. Different cases are based on the initial vessel pressure of the scaled-down test facility.

\section{Table 14}

Results of transient control volume analysis following depressurization

The most important factors to maintain hydrodynamic and heat transfer similarity are the air-tohelium mole ratio and the gas mixture's temperature. From Table 14, the final mixed mean temperature of the prototype geometry can be attained in the scaled-down test facility when the initial pressure of the scaled-down pressure vessel is $0.337 \mathrm{MPa}$ at an initial vessel temperature of $1023 \mathrm{~K}$. Also, the final air-to-helium mole ratio of the prototype geometry can be attained in the scaled-down test facility when the initial pressure of the scaled-down pressure vessel is 0.377 $\mathrm{MPa}$ at an initial vessel temperature of $1023 \mathrm{~K}$. Therefore, both initial conditions $(0.337 \mathrm{MPa}$, $0.377 \mathrm{MPa})$ will be imposed on separate high-temperature experiments $(1023 \mathrm{~K})$ in order to identically capture one of the two critical factors - air-to-helium mole ratio or final mixed mean temperature - in each experiment.

\subsection{Scaled-down Test Facility Design Specifications}

Incorporating the analyses and design discussed in the current paper, a $1 / 8^{\text {th }}$ scaled-down test facility has been constructed to examine the initial stages of a VHTR air-ingress accident. The as-built dimensions and specifications of the main test vessel and containment vessel are summarized in Table 15. 


\section{Table 15}

Scaled-down test facility as-built dimensions and specifications

The scaled-down test facility has instrumentation to measure the $\mathrm{O}_{2}$ concentration of the airhelium mixture, fluid pressure, fluid temperature, and fluid velocity. $\mathrm{O}_{2}$ concentration is measured using Teledyne Model $9060 \mathrm{H}$ Oxygen Analyzer probe. The facility also has the capability to non-intrusively measure $\mathrm{O}_{2}$ concentration with the assistance of a LaVision Planar Laser-Induced Fluorescence system. Fluid pressure is measured with ST 3000 Smart Pressure Transmitter Model STG944. Fluid temperature is measured using 1/8" Super OMEGACLAD XL K-type thermocouple probes. Fluid velocity is measured using a LaVision Particle Image Velocimetry (PIV) system. Table 16 outlines details regarding the instrumentation in the scaleddown test facility.

\section{Table 16}

Instrumentation of the scaled-down test facility

\section{Conclusion}

A physical description for a $1 / 8^{\text {th }}$ geometric scaled-down (by height and diameter), hightemperature test facility that models the hot duct-hot exit plenum system of a VHTR is presented. This model provides reliable data by ensuring one-to-one similarity of the Froude number and very close similarity of the resistance number while convective currents pass through the system. In fact, the average similarity ratio of the resistance number is 1.007 , which shows a negligible deviation of one-to-one similarity of the resistance number. Also, the distribution of the pressure loss in the scaled-down test facility is consistent with the distribution of the pressure loss in the prototypic facility. In the scaled-down design, when the pressure vessel is initially filled with helium to a pressure of $0.308 \mathrm{MPa}$, the transient depressurization occurs in $0.01 \mathrm{~s}$, an order of magnitude faster than the the prototype design. However, in both geometry types, the vessel 
helium temperature rises quickly, immediately after the depressurization, to higher temperature to facilitate buoyancy flows into the plenum. The time scale of the depressurization transient is three orders of magnitude smaller than the overall time scale of the air-ingress accident. The scaled-down facility accelerates the air-ingress phenomenon by a factor of 2.76 as compared to the protoypic design. CFD simulations confirm that the time scale of the air-ingress phenomenon during a double-ended guillotine break on the scaled-down test facility is on the same order of magnitude as the calculations based on the experimental data from Lowe et al. (2005).

The overall natural circulation phenomenology is preserved from the prototype geometry to the scaled-down test facility as the range of heat transfer coefficients overlap and are overall quite similar. The support column surface temperature profile is maintained for both types of geometry. In addition, the feasibility of a shell/heater system is discussed to decrease start-up time for elevated temperature experiments. An operational heater power $(125 \mathrm{~W})$ is found for the shell/heater system so that the surface temperature profile of the graphite cylinders is similar to that of the other two geometries thereby preserving the natural circulation phenomenology in the hot duct-hot plenum system of the air-ingress transient.

A free volume for the containment vessel of the scaled-down test facility is determined based on an initial vessel pressure of approximately $0.308 \mathrm{MPa}$. With this initial vessel pressure, the equilibrium temperature of the gas mixture in the scaled-down pressure vessel-containment vessel system is very close to that of the prototypic case. Additionally, the initial species composition of the gas mixture in the containment vessel can be controlled to alter the air-tohelium mole ratio so that there is better similarity to the prototypic case. This allows experiments to be performed that mimic the initial conditions of the density-driven stratified flow following 
the reactor vessel depressurization. Utilizing these scaling and design analyses, a $1 / 8^{\text {th }}$ scaleddown test facility has been constructed and instrumented.

\section{Acknowledgement}

This research is being performed using funding received from the U.S. Department of Energy's Office of Nuclear Energy's Nuclear Energy University Programs under DOE project number 09158.

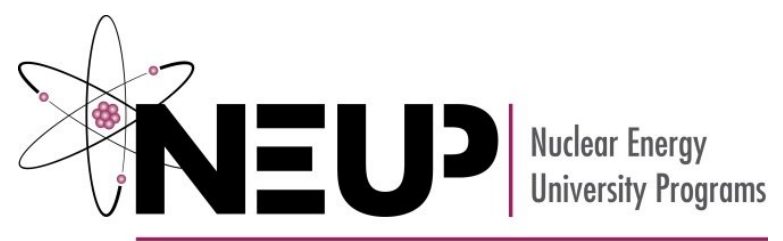

\section{U.S. Department of Energy}

\begin{tabular}{|ll|}
\hline Nomenclature \\
$a_{i}$ & cross-sectional area of the $i^{\text {th }}$ segment $\left(\mathrm{m}^{2}\right)$ \\
$a_{r}$ & cross-sectional area of the reference segment $\left(\mathrm{m}^{2}\right)$ \\
$A_{c}$ & cross-sectional area of the hot duct $\left(\mathrm{m}^{2}\right)$ \\
$A_{s}$ & support column/graphite cylinder surface area $\left(\mathrm{m}^{2}\right)$ \\
$A_{s c}$ & support column/graphite cylinder cross-sectional area $\left(\mathrm{m}^{2}\right)$ \\
$\mathrm{Bi}$ & Biot number \\
$c_{p}$ & support column/graphite cylinder $(\mathrm{IG}-110 \quad$ graphite $) \quad$ specific heat capacity \\
$c_{p, a}$ & air specific heat capacity in the vessel $(\mathrm{J} /(\mathrm{kg}-\mathrm{K}))$ \\
$c_{p, h e}$ & helium specific heat capacity at constant pressure $(\mathrm{J} /(\mathrm{kg}-\mathrm{K}))$ \\
$c_{p, w}$ & average specific heat capacity at constant pressure of vessel solid internals \\
$c_{v, h e}$ & $(\mathrm{~J} /(\mathrm{kg}-\mathrm{K}))$ \\
$c_{v_{i}, a}$ & helium specific heat capacity at constant volume $(\mathrm{J} /(\mathrm{kg}-\mathrm{K}))$ \\
$c_{v_{i}, h e}$ & initial air specific heat capacity at constant volume $(\mathrm{J} /(\mathrm{kg}-\mathrm{K}))$ \\
$c_{v_{f}, a}$ & initial helium specific heat capacity at constant volume $(\mathrm{J} /(\mathrm{kg}-\mathrm{K}))$ \\
$c_{v_{f}, h e}$ & final helium specific heat capacity at constant volume $(\mathrm{J} /(\mathrm{kg}-\mathrm{K}))$ \\
$D_{A B}$ & final helium specific heat capacity at constant volume $(\mathrm{J} /(\mathrm{kg}-\mathrm{K}))$ \\
$d_{h}$ & binary diffusion coefficient $\left(\mathrm{m}^{2} / \mathrm{s}\right)$
\end{tabular}




\begin{tabular}{|c|c|}
\hline$f$ & Darcy friction factor \\
\hline$g$ & acceleration due to gravity $\left(9.8 \mathrm{~m} / \mathrm{s}^{2}\right)$ \\
\hline$H$ & $\begin{array}{l}\text { vertical distance between the thermal centers of the hot and cold side/channel } \\
\text { depth }(\mathrm{m})\end{array}$ \\
\hline$H_{o}$ & geometric height of the reference section (m) \\
\hline$H_{s c}$ & support column/graphite cylinder height $(\mathrm{m})$ \\
\hline$H^{+}$ & $\begin{array}{l}\text { dimensionless vertical distance between the thermal centers of the hot and cold } \\
\text { side }\end{array}$ \\
\hline$h$ & natural/forced convection heat transfer coefficient $\left(\mathrm{W} /\left(\mathrm{m}^{2}-\mathrm{K}\right)\right)$ \\
\hline$h_{L}$ & current depth $(\mathrm{m})$ \\
\hline$K$ & minor (form) loss coefficient \\
\hline$K_{c}$ & pressure loss coefficient for a sudden contraction \\
\hline$k$ & $\begin{array}{l}\text { support column/graphite cylinder (IG-110 graphite) thermal conductivity } \\
(\mathrm{W} /(\mathrm{m}-\mathrm{K}))\end{array}$ \\
\hline$K_{T, i}$ & total pressure loss coefficient for the $i^{\text {th }}$ segment \\
\hline$L_{\text {Diff }}$ & length scale for molecular diffusion time scale analysis (m) \\
\hline$L_{D D}$ & length scale for density-driven air ingress time scale analysis (m) \\
\hline$l$ & hot duct length $(\mathrm{m})$ \\
\hline$l_{i}$ & length of the $i^{\text {th }}$ segment $(\mathrm{m})$ \\
\hline$m$ & subscript denoting scaled-down model \\
\hline$m^{2}$ & support column/graphite cylinder inverse characteristic length $\left(1 / \mathrm{m}^{2}\right)$ \\
\hline$m_{o}$ & initial mass of helium in the vessel $(\mathrm{kg})$ \\
\hline$M_{A}$ & molecular weight of species $A(\mathrm{~kg} / \mathrm{kmol})$ \\
\hline$M_{B}$ & molecular weight of species $B(\mathrm{~kg} / \mathrm{kmol})$ \\
\hline$m_{a}$ & air mass in the reactor vessel/containment closed system $(\mathrm{kg})$ \\
\hline$m_{a, i}$ & initial air mass in the containment vessel $(\mathrm{kg})$ \\
\hline$m_{a, f}$ & final air mass in the containment vessel $(\mathrm{kg})$ \\
\hline$m_{a}(t)$ & air mass as a function of time that diffuses into the hot duct $(\mathrm{kg})$ \\
\hline$m_{e}$ & air mass exited the reactor vessel/containment system $(\mathrm{kg})$ \\
\hline$m_{h e}$ & helium mass in the reactor vessel/containment closed system $(\mathrm{kg})$ \\
\hline$m_{h e}(t)$ & helium mass in the vessel as a function of time $(\mathrm{kg})$ \\
\hline$\dot{m}$ & mass flow rate of air-helium mixture $(\mathrm{kg} / \mathrm{s})$ \\
\hline$\dot{m}_{h e}(t)$ & helium exit mass flow rate as a function of time $(\mathrm{kg} / \mathrm{s})$ \\
\hline$\dot{m}_{i}$ & mass flow rate of air-helium mixture in the $i^{\text {th }}$ segment $(\mathrm{kg} / \mathrm{s})$ \\
\hline$\dot{m}_{o}$ & mass flow rate of air-helium mixture at initiation of DDAI event $(\mathrm{kg} / \mathrm{s})$ \\
\hline$\dot{m}^{+}$ & dimensionless mass flow rate of air-helium mixture \\
\hline$N u$ & Nusselt number \\
\hline$p$ & subscript denoting prototypic design \\
\hline
\end{tabular}




\begin{tabular}{|c|c|}
\hline$P$ & absolute pressure (atm) \\
\hline$P(t)$ & helium global pressure in the reactor vessel as a function of time $(\mathrm{Pa})$ \\
\hline$P_{a m b}$ & air-helium gas mixture containment pressure $(\mathrm{Pa})$ \\
\hline$P_{o}$ & steady-state operating power level (W) \\
\hline$P_{w}$ & wetted perimeter $(\mathrm{m})$ \\
\hline$\dot{Q}$ & total heater power $(\mathrm{W})$ \\
\hline$q_{\text {bottom }}^{\prime \prime}$ & $\begin{array}{l}\text { heat flux through the bottom surface of the support column/graphite cylinder } \\
\left(\mathrm{W} / \mathrm{m}^{2}\right)\end{array}$ \\
\hline$r$ & radial variable $(\mathrm{m})$ \\
\hline$r_{1}$ & inner radius of support column/graphite cylinder (m) \\
\hline$r_{2}$ & outer radius of support column/graphite cylinder (m) \\
\hline$R$ & $\begin{array}{l}\text { ratio of the scaled-down model resistance number to the prototypic resistance } \\
\text { number }\end{array}$ \\
\hline$R a$ & Rayleigh number \\
\hline$t$ & time (s) \\
\hline$t^{+}$ & dimensionless time \\
\hline$T$ & gas temperature $(\mathrm{K})$ \\
\hline$T_{a, i}$ & initial air temperature $(\mathrm{K})$ \\
\hline$T_{\text {bottom }}$ & temperature at the bottom of the support column/graphite cylinder $\left({ }^{\circ} \mathrm{C}\right)$ \\
\hline$T_{f}$ & final temperature of air-helium gas mixture $(\mathrm{K})$ \\
\hline$T_{h e}(t)$ & helium bulk temperature in the vessel as a function of time $(\mathrm{K})$ \\
\hline$T_{h e, i}$ & initial helium temperature $(\mathrm{K})$ \\
\hline$T_{\text {inf }}$ & far-field air-helium gas mixture temperature $\left({ }^{\circ} \mathrm{C}\right)$ \\
\hline$T_{\text {top }}$ & temperature at the top of the support column/graphite cylinder $\left({ }^{\circ} \mathrm{C}\right)$ \\
\hline$T_{w}(t)$ & average temperature of vessel solid internals as a function of time (K) \\
\hline$U$ & gravity current speed $(\mathrm{m} / \mathrm{s})$ \\
\hline$U_{s}$ & superficial velocity $(\mathrm{m} / \mathrm{s})$ \\
\hline$v(t)$ & helium exit velocity from the reactor vessel as a function of time $(\mathrm{m} / \mathrm{s})$ \\
\hline$v_{i}$ & fluid velocity in the $i^{\text {th }}$ segment $(\mathrm{m} / \mathrm{s})$ \\
\hline$V$ & support column/graphite cylinder volume $\left(\mathrm{m}^{3}\right)$ \\
\hline$V_{w}$ & volume of vessel solid internals $\left(\mathrm{m}^{3}\right)$ \\
\hline$w_{C}$ & average fluid velocity inside the reactor's enclosure $(\mathrm{m} / \mathrm{s})$ \\
\hline$w_{C}^{+}$ & dimensionless average fluid velocity inside the reactor's enclosure \\
\hline$w_{H}$ & average fluid velocity inside the reactor's hot exit plenum (m/s) \\
\hline$w_{H}^{+}$ & dimensionless average fluid velocity inside the reactor's hot exit plenum \\
\hline$w_{o}$ & velocity of the reference section at the onset of natural circulation $(\mathrm{m} / \mathrm{s})$ \\
\hline$z$ & axial variable $(\mathrm{m})$ \\
\hline$z^{+}$ & dimensionless axial variable \\
\hline
\end{tabular}




\begin{tabular}{|c|c|}
\hline$\alpha$ & kinetic energy coefficient \\
\hline$\gamma$ & density ratio $\left(\rho_{1} / \rho_{2}<1\right)$ \\
\hline$\Delta P_{d}$ & natural circulation driving force $(\mathrm{Pa})$ \\
\hline$\Delta P_{r e s}$ & resistance pressure drop $(\mathrm{Pa})$ \\
\hline$\Pi_{F}$ & resistance number \\
\hline$\Pi_{F r}$ & modified Froude number \\
\hline$\Pi_{L}$ & geometric non-dimensional group \\
\hline$\theta(z)$ & excess temperature $\left({ }^{\circ} \mathrm{C}\right)$ \\
\hline$\theta_{\text {bottom }}$ & excess temperature at the bottom of the support column/graphite cylinder $\left({ }^{\circ} \mathrm{C}\right)$ \\
\hline$\theta_{\text {top }}$ & excess temperature at the top of the support column/graphite cylinder $\left({ }^{\circ} \mathrm{C}\right)$ \\
\hline $\bar{\theta}$ & average excess temperature $\left({ }^{\circ} \mathrm{C}\right)$ \\
\hline$\rho$ & support column/graphite cylinder (IG-110 graphite) density $\left(\mathrm{kg} / \mathrm{m}^{3}\right)$ \\
\hline$\rho_{a}(z, t)$ & air density as a function of axial position and time $\left(\mathrm{kg} / \mathrm{m}^{3}\right)$ \\
\hline$\rho_{a, s}$ & $\rho_{A}(0, t)$ at $z=0$ for all $t\left(\mathrm{~kg} / \mathrm{m}^{3}\right)$ \\
\hline$\rho_{\text {avg }}$ & average helium density in the hot duct $\left(\mathrm{kg} / \mathrm{m}^{3}\right)$ \\
\hline$\rho_{C}$ & average fluid density inside the reactor's enclosure $\left(\mathrm{kg} / \mathrm{m}^{3}\right)$ \\
\hline$\left(\rho_{C}-\rho_{H}\right)_{o}$ & $\begin{array}{l}\text { density difference between the fluid in the reactor's enclosure (cold side) and the } \\
\text { fluid in the reactor's hot exit plenum (hot side) at the onset of natural circulation } \\
\left(\mathrm{kg} / \mathrm{m}^{3}\right)\end{array}$ \\
\hline$\rho_{C}^{+}$ & dimensionless average fluid density inside the reactor's enclosure \\
\hline$\rho_{H}$ & average fluid density inside the reactor's hot exit plenum $\left(\mathrm{kg} / \mathrm{m}^{3}\right)$ \\
\hline$\rho_{H}^{+}$ & dimensionless average fluid density inside the reactor's hot exit plenum \\
\hline$\rho_{i}$ & fluid density in the $i^{\text {th }}$ segment \\
\hline$\rho_{r}$ & average fluid density of the reference segment $\left(\mathrm{kg} / \mathrm{m}^{3}\right)$ \\
\hline$\rho_{w}$ & average density of vessel solid internal $\left(\mathrm{kg} / \mathrm{m}^{3}\right)$ \\
\hline$\sigma_{A B}$ & collision diameter (Lennard-Jones parameter, $\AA$ ) \\
\hline$\tau$ & characteristic time scale (s) \\
\hline$\tau_{D D}$ & time scale of density-driven air ingress phenomenon (s) \\
\hline$\tau_{\text {Diff }}$ & time scale of air-helium molecular diffusion phenomenon (s) \\
\hline$\tau_{\text {thermal }}$ & time scale natural circulation phenomenon (s) \\
\hline$\tau_{\text {total }}$ & air-ingress time scale (s) \\
\hline$\Omega_{D}$ & collision integral \\
\hline
\end{tabular}




\section{Biographies}

\section{References}

Arcilesi, D.J., Ham, T.K., Sun, X., Christensen, R.N., Oh, C.H., 2012. Scaling and Developmental Analysis for the Construction of a Scaled-down, High-temperature Test Facility for the Experimental Investigation of the Initial Stages of a VHTR Air-ingress Accident. In: Advances in Thermal Hydraulics (ATH'12) Conference Proceedings, San Diego, CA, 72-81.

Arcilesi, D.J., Ham, T.K., Sun, X., Christensen, R.N., Oh, C.H., 2013. Boundary and Initial Conditions of Scaled-down, High-temperature Experiments for Initial Stages of VHTR Airingress Accidents. In: The $15^{\text {th }}$ International Topical Meeting on Nuclear Reactor ThermalHydraulics, NURETH-15, Pisa, Italy, Paper ID: 467.

Banerjee, A., Andrews, M.J., 2007. A Convection Heat Transfer Correlation for a Binary AirHelium Mixture at Low Reynolds Number. Journal of Heat Transfer, 129, 1494-1505.

Chapman, S., Cowling, T.G., 1970. The Mathematical Theory of Non-uniform Gases: An Account of the Kinetic Theory of Viscosity, Thermal Conduction and Diffusion in Gases, $3^{\text {rd }}$ Edition, Cambridge University Press, Cambridge, UK.

General Atomics, 1996. Gas Turbine-Modular Helium Reactor (GT-MHR) Conceptual Design Description Report, General Atomics, GA Project No. 7658, 910720 Revision 1.

Ham, T.K., Arcilesi, D.J., Sun, X., Christensen, R.N., Oh, C.H., Kim, E.S., 2012. Preliminary CFD Calculations for OSU Air-Ingress Experimental Facility. Transactions of the American Nuclear Society, 107, 1290-1292. 
Hishida, M., Takeda, T., 1991. Study on air ingress during an early stage of a primary-pipe rupture accident of a high-temperature gas-cooled reactor. Nuclear Engineering and Design, $126,175-187$.

Holman, J.P., 1976. Heat Transfer, $4^{\text {th }}$ Edition, McGraw-Hill, Inc.

Idelchik, I.E., 1986. Handbook of Hydraulic Resistance, $2^{\text {nd }}$ Edition. Hemisphere Publishing Corporation, New York, New York.

Jin, H.G., No, H.C., Kim, H.I., 2011. Stratified flow-induced air-ingress accident assessment of the GAMMA code in HTGRs. Nuclear Engineering and Design, 241, 3216-3223.

Jin, H.G., No, H.C., Park, B.H., 2012. Effects of the onset time of natural circulation on safety in an air ingress accident involving a HTGR. Nuclear Engineering and Design, 250, 626-632.

Kim, E.S., No, H.C., Kim, B., Oh, C.H., 2008. Estimation of graphite density and mechanical strength variation of VHTR during air-ingress accident. Nuclear Engineering and Design, $238,837-847$

Kodochigov, N., Sukharev, Y., Marova, E., Ponomarev-Stepnoy, N., Glushkov, E., Fomichenko, P., 2003. Neutronic features of the GT-MHR reactor. Nuclear Engineering and Design, 222, $161-171$

Latini, G., Passerini, G., Polonara, F., 1996. Thermophysical Properties of Greenhouse Gases Thermal Conductivity and Dynamic Viscosity as Function of Temperature and Pressure. Energy Conversion and Management, 37, No. 6-8, 1291-1296.

Lowe, R.J., Rottman, J.W., Linden, P.F., 2005. The non-Boussinesq lock-exchange problem. Part 1. Theory and experiments. Journal of Fluid Mechanics, 537, 101-124. 
MacDonald, P.E., Sterbentz, J.W., Sant, R.L., Bayless, P., Gougar, H.D., Moore, R.L., Ougouag, A.M., Terry, W.K., 2003. NGNP Point Design - Results of the Initial Neutronics and Thermal-Hydraulic Assessments During FY-03, INEEL/EXT-03-00870, Idaho National Laboratory, Idaho Falls, ID.

Maruyama, T., Kaito, T., Onose, S, Shibahara, I., 1995. Change in physical properties of high density isotropic graphites irradiated in the "JOYO" fast reactor. Journal of Nuclear Material, $225,267-272$.

McEligot, D.M., Condie, K.G., McGreery, G.E., McIlroy, H.M., 2005. Development of an Experiment for Measuring Flow Phenomena Occurring in a Lower Plenum for VHTR CFD Assessment, INL/EXT-05-00603, Idaho National Laboratory, Idaho Falls, ID.

Neylan, A.J., Shenoy, A., Silady, F.A., Dunn, T.D., 1994. GT-MHR Design, Performance and Safety, General Atomics, Inc. GA-A21924, General Atomics Project 7600.

No, H.C., Lim, H.S., Kim, J., Oh, C.H., Siefken, L., Davis, C., 2008. Multi-component diffusion analysis and assessment of GAMMA code and improved RELAP5 code. Nuclear Engineering and Design, 237, 997-1008.

Oh, C.H., Davis, C., Siefken, L., Moore, R., No, H.C., Kim, J., Park, G.C., Lee, J.C., Martin, W.R., 2006. Development of Safety Analysis Codes and Experimental Validation for a Very High Temperature Gas-Cooled Reactor, INL/EXT-06-01362, Idaho National Laboratory, Idaho Falls, ID. 
Oh, C.H., Kim, E.S., No, H.C., Cho, N.Z., 2008. Experimental Validation of Stratified Flow Phenomena, Graphite Oxidation, and Mitigation Strategies of Air Ingress Accident, INL/EXT-08-14840, Idaho National Laboratory, Idaho Falls, ID.

Oh, C.H., Kim, E.S., No, H.C., Cho, N.Z., 2009. Experimental Validation of Stratified Flow Phenomena, Graphite Oxidation, and Mitigation Strategies of Air Ingress Accident, INL/EXT-09-16465, Idaho National Laboratory, Idaho Falls, ID.

Oh, C.H., Kim, E.S., 2011. Air-ingress analysis: Part 1. Theoretical approach. Nuclear Engineering and Design, 241, 203-212.

Oh, C.H., Kang, H.S., Kim, E.S., 2011. Air-ingress analysis: Part 2 - Computational fluid dynamic models. Nuclear Engineering and Design, 241, 213-225.

Petersen, H., 1970. The Properties of Helium: Density, Specific Heats, Viscosity, and Thermal Conductivity at Pressures from 1 to 100 bar and from Room Temperature to about $1800 \mathrm{~K}$, Risö Report No. 224.

Reyes Jr., J.N., Groome, J.T., Woods, B.G., Jackson, B., Marshall, T.D., 2010. Scaling analysis for the high temperature Gas Reactor Test Section (GRTS). Nuclear Engineering and Design, $240,397-404$.

Reza, S.M.M., Harvego, E.A., Richards, M., Shenoy, A., Peddicord, K.L., 2006. Design of an Alternative Coolant Inlet Flow Configuration for the Modular Helium Reactor, INL/CON06-01348, Idaho National Laboratory, Idaho Falls, ID.

Shaber, E., Baccaglini, G., Ball, S., Burchell, T., Corwin, B., Fewell, T., Labar, M., MacDonald, P., Rittenhouse, P., Vollam, R., Southworth, F., 2003. VHTR - Survey of Materials Research 
and Development Needs to Support Early Deployment, INEEL/EXT-03-00141, Idaho National Laboratory, Idaho Falls, ID.

Tak, N., Kim, M., Lee, W.J., 2008. Numerical investigation of a heat transfer within the prismatic fuel assembly of a very high temperature reactor. Annals of Nuclear Energy, 35, 1892-1899.

Takeda, T., Hishida, M., 1996. Studies on molecular diffusion and natural convection in a multicomponent gas system. International Journal of Heat and Mass Transfer, 39, 527-536.

Todreas, N.E., Kazimi, M.S., 1993. Nuclear Systems I: Thermal Hydraulic Fundamentals, $1^{\text {st }}$ Edition. Taylor \& Francis, Levittown, Pennsylvania.

Xia, J.L., Smith, B.L., Yadigaroglu, G., 1993. A Simplified Model for Depressurization of Gasfilled Pressure Vessels. International Communications of Heat and Mass Transfer, 20, 653664.

Zografos, A.I., Martin, W.A., Sunderland, J.E., 1987. Equations of Properties as a Function of Temperature for Seven Fluids. Computer Methods in Applied Mechanics and Engineering, $61,177-187$. 


\section{List of Tables}

Table 1. List of key dimensions for GT-MHR pressure vessel

Table 2. Gravity current speed and depth for air-ingress accident time scale analysis

Table 3. Summary of air-ingress phenomenon time scales

Table 4. Types of pressure loss considered for each section of the test facility

Table 5. Species composition and temperature for each segment for single-species calculations

Table 6. Species composition and temperatures for each segment for mixed-species calculations

Table 7. Resultant support column pitches and diameters

Table 8. Resistance number similarity ratio for each case

Table 9. Loop pressure loss distribution of prototypic and scaled-down geometries

Table 10. Boundary conditions for a 2D temperature profile analysis

Table 11. Parameters for containment vessel free volume calculation

Table 12. Scaled-down containment free volume for different initial vessel pressures

Table 13. Initial conditions for final mixture temperature analysis for the prototype and scaleddown geometry

Table 14. Results of transient control volume analysis following depressurization

Table 15. Scaled-down test facility as-built dimensions and specifications

Table 16. Instrumentation of the scaled-down test facility 
Fig. 1. (a) GT-MHR reactor vessel and (b) enlarged hot duct-hot exit plenum system

Fig. 2. (a) Side view of scaled-down test facility (b) cut view of main test vessel and (c) top view of hot exit plenum in main test vessel

Fig. 3. The gas-turbine modular helium reactor with key parameters indicated

Fig. 4. Flow depth of the heavy current (Lowe et el., 2005)

Fig. 5. Average Biot numbers for prototypic conditions

Fig. 6. Average Biot numbers for scaled-down conditions

Fig. 7. Average thermal time constant for prototypic conditions

Fig. 8. Average thermal time constant for scaled-down conditions

Fig. 9. Progression of air plume during a density-driven air ingress event in the test section at time: (a) $t=0.6 \mathrm{~s}$, (b) $t=1.1 \mathrm{~s}$, (c) $t=1.85 \mathrm{~s}$, (d) $t=3.1 \mathrm{~s}$, (e) $t=4.1 \mathrm{~s}$, and (f) $t=4.6 \mathrm{~s}$ following the break initiation

Fig. 10. Helium temperature versus time during depressurization of the prototypic vessel

Fig. 11. Helium temperature versus time during depressurization of the scaled-down facility

Fig. 12. Hot duct-hot exit plenum system with control volumes outlined

Fig. 13. Overhead view of the propagation of the air plume at the bottom of the test section at time: (a) $t=0.6 \mathrm{~s}$, (b) $t=1.1 \mathrm{~s}$, (c) $t=1.85 \mathrm{~s}$, (d) $t=3.1 \mathrm{~s}$, (e) $t=4.1 \mathrm{~s}$, and (f) $t=4.6 \mathrm{~s}$ following the break initiation

Fig. 14. Top view of bottom plate with instrumentation ports to measure initial air ingress plume

Fig. 15. Average heat transfer coefficient vs. air mole fraction for the prototype geometry

Fig. 16. Average heat transfer coefficient vs. air mole fraction for the scaled-down geometry

Fig. 17. (a) Overhead view of case (C) and (b) Side cut view of scaled-down shell/heater system of case (C)

Fig 18. Temperature contour plot of prototypic support column (Case A) at $t=6 \tau t$ totalTemperature 
Fig. 19. Temperature contour plot of scaled-down test facility graphite cylinder (Case B) at $t=$ 6ttotalTemperature contour plot of scaled-down test facility graphite cylinder (Case B)

Fig. 20. Temperature contour plot of scaled-down test facility shell/heater system for $125 \mathrm{~W}$ (Case C) at $t=3 \tau_{\text {total }}$ 


\section{Table 1}

List of key dimensions for GT-MHR pressure vessel

\begin{tabular}{lll}
\hline Parameters & Prototype $(\mathrm{m})$ & $1 / 8^{\text {th }}(\mathrm{m})$ \\
\hline Vessel Height & 23.7 & 2.963 \\
Vessel Inner Diameter & 7.8 & 0.975 \\
Vessel Outer Diameter & 8.4 & 1.050 \\
Core Height & 11 & 1.375 \\
Active Core Height & 7.8 & 0.975 \\
Support Column Height & 2.84 & 0.355 \\
Cold Duct Outer Diameter & 2.29 & 0.286 \\
Hot Duct Diameter & 1.5 & 0.1875 \\
Hot Duct Length & 2.86 & $0.3575^{\mathrm{a}}(0.2032)$ \\
Support Column Diameter & 0.212 & $0.0265^{\mathrm{a}}(0.052)$ \\
Support Column Pitch & 0.36 & $0.045^{\mathrm{a}}(0.088)$ \\
Hot Exit Plenum Diameter & 6.8 & 0.85 \\
\hline
\end{tabular}

${ }^{\mathrm{a}}$ Not actual dimensions of the $1 / 8^{\text {th }}$ scaled-down facility 
Table 2

Gravity current speed and depth for air-ingress accident time scale analysis

\begin{tabular}{llllllll}
\hline Case & Species & $\begin{array}{l}\text { Thermodynamic } \\
\text { State }\end{array}$ & $\begin{array}{l}\text { Density } \\
\text { Ratio }\end{array}$ & $\begin{array}{l}\text { Depth } \\
\text { Ratio }\end{array}$ & $\begin{array}{l}\text { Pipe } \\
\text { Diameter }(\mathrm{m})\end{array}$ & $\begin{array}{l}\text { Current } \\
\text { Depth }(\mathrm{m})\end{array}$ & $\begin{array}{l}\text { Current } \\
\text { Speed }(\mathrm{m} / \mathrm{s})\end{array}$ \\
\hline Prototype & $\begin{array}{l}\text { Helium } \\
\text { Air }\end{array}$ & $\begin{array}{l}850^{\circ} \mathrm{C}, 1 \mathrm{~atm} \\
25^{\circ} \mathrm{C}, 1 \mathrm{~atm}\end{array}$ & 0.037 & & 1.5 & 0.06 & 5.286 \\
\cline { 1 - 2 } $\begin{array}{l}\text { Scaled- } \\
\text { down }\end{array}$ & $\begin{array}{l}\text { Helium } \\
\text { Air }\end{array}$ & $\begin{array}{l}750^{\circ} \mathrm{C}, 1 \mathrm{~atm} \\
25^{\circ} \mathrm{C}, 1 \mathrm{~atm}\end{array}$ & 0.040 & & 0.1875 & 0.0075 & 1.780 \\
\hline
\end{tabular}


Table 3

Summary of air-ingress phenomenon time scales

\begin{tabular}{lllll}
\hline Geometry & DDAI $(\mathrm{s})$ & HPNC $(\mathrm{s})$ & Diffusion $(\mathrm{s})$ & Total $(\mathrm{s})$ \\
\hline Prototype & 16.08 & 14,008 & 14,160 & 16.04 \\
Scaled-down & 5.97 & 3,299 & 258 & 5.82 \\
\hline
\end{tabular}


Table 4

Types of pressure loss considered for each section of the test facility

\begin{tabular}{|c|c|}
\hline Section Number & Types of Pressure Loss Considered \\
\hline 1,5 & a. Frictional pressure loss \\
\hline 2,4 & $\begin{array}{l}\text { a. Expansion pressure loss }(1 \rightarrow 2) \\
\text { b. Contraction pressure loss }(4 \rightarrow 5) \\
\text { c. Pressure loss due to horizontal fluid motion } \\
\text { through a bank of tubes }\end{array}$ \\
\hline 3 & a. Frictional pressure loss \\
\hline
\end{tabular}


Table 5

Species composition and temperature for each segment for single-species calculations

\begin{tabular}{llll}
\hline Case & Species Composition & Cold Temperature $\left({ }^{\circ} \mathrm{C}\right)$ & Average Temperature $\left({ }^{\circ} \mathrm{C}\right)$ \\
\hline 1 & & 25 & 437.5 \\
2 & $100 \%$ Helium & 170 & 510 \\
3 & & 500 & 675 \\
\hline 4 & & 25 & 437.5 \\
5 & $100 \%$ Air & 170 & 510 \\
6 & & 500 & 675 \\
\hline
\end{tabular}


Table 6

Species composition and temperatures for each segment for mixed-species calculations

\begin{tabular}{llll}
\hline Segments & $(1)$ and $(2)$ & $(3)$ & $(4)$ and $(5)$ \\
\hline Species Composition & $80 \%$ Air/20\% Helium & $50 \%$ Air $/ 50 \%$ Helium & $20 \%$ Air/80\% Helium \\
\hline Case & & Temperature $\left({ }^{\circ} \mathrm{C}\right)$ & \\
\hline 7 & 25 & 437.5 & 850 \\
8 & 170 & 510 & \\
9 & 500 & 675 & \\
\hline
\end{tabular}


Table 7

Resultant support column pitches and diameters

\begin{tabular}{lll}
\hline Case & SC Pitch $(\mathrm{cm})$ & SC Diameter $(\mathrm{cm})$ \\
\hline 1 & 11.8 & 6.9 \\
2 & 15.2 & 8.9 \\
4 & 7.2 & 4.2 \\
5 & 7.1 & 4.2 \\
6 & 10.0 & 5.9 \\
7 & 6.6 & 3.9 \\
8 & 6.2 & 3.7 \\
9 & 6.5 & 3.8 \\
\hline Average & 8.8 & 5.2 \\
\hline
\end{tabular}


Table 8

Resistance number similarity ratio for each case

\begin{tabular}{ll}
\hline Case & Similarity Ratio $(R)$ \\
\hline 1 & 0.991 \\
2 & 0.998 \\
4 & 0.969 \\
5 & 0.980 \\
6 & 1.017 \\
7 & 1.055 \\
8 & 1.040 \\
9 & 1.008 \\
\hline Average & 1.007 \\
\hline
\end{tabular}


Table 9

Loop pressure loss distribution of prototypic and scaled-down geometries

\begin{tabular}{|c|c|c|c|c|c|c|c|}
\hline Case & Geometry Type & Segment $1(\%)$ & Segment $2(\%)$ & Segment $3(\%)$ & Segment $4(\%)$ & Segment $5(\%)$ & $\begin{array}{l}\text { Total Pressure } \\
\text { Loss }(\mathrm{Pa}) \\
\end{array}$ \\
\hline \multirow{2}{*}{1} & Prototype & 3.53 & 13.43 & 0.20 & 66.08 & 16.76 & 2.67 \\
\hline & Scaled-down & 2.13 & 12.31 & 0.66 & 64.64 & 20.26 & 0.33 \\
\hline \multirow{2}{*}{2} & Prototype & 5.51 & 19.19 & 0.31 & 58.54 & 16.45 & 1.33 \\
\hline & Scaled-down & 5.58 & 15.21 & 0.62 & 51.39 & 27.20 & 0.17 \\
\hline \multirow{2}{*}{4} & Prototype & 3.50 & 15.77 & 0.06 & 64.85 & 15.82 & 18.93 \\
\hline & Scaled-down & 1.97 & 15.30 & 0.30 & 73.13 & 9.30 & 2.37 \\
\hline \multirow{2}{*}{5} & Prototype & 4.95 & 21.95 & 0.05 & 58.87 & 14.18 & 9.53 \\
\hline & Scaled-down & 2.89 & 21.58 & 0.45 & 67.33 & 7.75 & 1.19 \\
\hline \multirow{2}{*}{6} & Prototype & 8.31 & 31.18 & 0.12 & 47.62 & 12.77 & 2.33 \\
\hline & Scaled-down & 4.02 & 34.57 & 0.55 & 53.52 & 7.34 & 0.29 \\
\hline \multirow{2}{*}{7} & Prototype & 1.49 & 6.13 & 0.03 & 74.26 & 18.09 & 19.22 \\
\hline & Scaled-down & 0.78 & 7.77 & 0.04 & 81.46 & 9.95 & 2.40 \\
\hline \multirow{2}{*}{8} & Prototype & 2.11 & 9.20 & 0.03 & 72.38 & 16.28 & 11.06 \\
\hline & Scaled-down & 1.15 & 11.20 & 0.06 & 78.46 & 9.13 & 1.38 \\
\hline \multirow{5}{*}{9} & Prototype & 3.83 & 16.61 & 0.04 & 63.94 & 15.58 & 4.54 \\
\hline & Scaled-down & 2.17 & 18.47 & 0.11 & 70.29 & 8.96 & 0.57 \\
\hline & $\begin{array}{l}\text { Avg. } \% \\
\text { Difference }\end{array}$ & 1.59 & 1.85 & 0.24 & 6.36 & 6.82 & \\
\hline & Largest \% Diff. & 4.29 & 3.98 & 0.46 & 8.45 & 10.75 & \\
\hline & Smallest \% & 0.07 & 0.36 & 0.01 & 1.44 & 3.49 & \\
\hline
\end{tabular}


Table 10

Boundary conditions for a 2D temperature profile analysis

\begin{tabular}{lllll}
\hline Case & $\begin{array}{l}\text { Top Boundary } \\
\text { Condition }\end{array}$ & $\begin{array}{l}\text { Bottom Boundary } \\
\text { Condition }\end{array}$ & $\begin{array}{l}\text { Left Boundary } \\
\text { Condition }\end{array}$ & Right Boundary Condition \\
\hline $\mathrm{A}$ & & $\left.\frac{\partial T}{\partial r}\right|_{r=0}=0$ & $-\left.k_{s} \frac{\partial T}{\partial r}\right|_{r=r_{2}}=h\left(T\left(r=r_{2}, z, t\right)-T_{\infty}\right)$ \\
$\mathrm{B}$ & $\begin{array}{l}\text { Fixed } \\
\text { Temperature }\end{array}$ & $\begin{array}{l}\text { Fixed } \\
\text { Temperature }\end{array}$ & $-\left.k_{s} \frac{\partial T}{\partial r}\right|_{r=r_{1}}=q_{\text {heater }}^{\prime \prime}$ & \\
$\mathrm{C}$ & $\left(750^{\circ} \mathrm{C}\right)$ & $\left(750^{\circ} \mathrm{C}\right)$ & &
\end{tabular}


Table 11

Parameters for containment vessel free volume calculation

\begin{tabular}{lllll}
\hline Case & Container Type & Free Volume $\left(\mathrm{m}^{3}\right)$ & Initial Pressure $(\mathrm{MPa})$ & Initial Temperature $\left({ }^{\circ} \mathrm{C}\right)$ \\
\hline \multirow{2}{*}{ Prototype } & Reactor Vessel & 265 & 7 & 850 \\
& Containment & 25,000 & 0.101 & 25 \\
\multirow{2}{*}{ Scaled-down } & Main Test Vessel & 0.210 & See Table 12 & 750 \\
& Containment Vessel & See Table 12 & 0.101 & 25 \\
\hline
\end{tabular}


Table 12

Scaled-down containment free volume for different initial vessel pressures

\begin{tabular}{lll}
\hline Initial Scaled-down Vessel Pressure $(\mathrm{psig})$ & Initial Vessel Temperature $\left({ }^{\circ} \mathrm{C}\right)$ & Scaled-down Containment Volume $\left(\mathrm{m}^{3}\right)$ \\
\hline $0(0.101 \mathrm{MPa})$ & 750 & 0.315 \\
$30(0.308 \mathrm{MPa})$ & 750 & 0.963 \\
$60(0.515 \mathrm{MPa})$ & 750 & 1.605 \\
\hline
\end{tabular}


Table 13

Initial conditions for final mixture temperature analysis for the prototype and scaled-down geometry

\begin{tabular}{lllll}
\hline & & Containment & Pressure Vessel \\
\hline & Prototype & Scaled-down & Prototype & Scaled-down \\
\hline Pressure $(\mathrm{MPa})$ & 0.101 & 0.101 & 7 & 0.308 \\
Volume $\left(\mathrm{m}^{3}\right)$ & 25,000 & 1 & 265 & 0.210 \\
Temperature $(\mathrm{K})$ & 298 & 298 & 1123 & 1023 \\
Species & $100 \%$ Air & $100 \%$ Air & $100 \%$ Helium & $100 \%$ Helium \\
\hline
\end{tabular}


Table 14

Results of transient control volume analysis following depressurization

\begin{tabular}{|c|c|c|c|}
\hline $\begin{array}{l}\text { Geometry Type (Initial Vessel } \\
\text { Pressure) }\end{array}$ & Final Temperature $(\mathrm{K})$ & $\begin{array}{l}\text { Percent of Initial Air } \\
\text { Mass Lost }\end{array}$ & Final Air/He Mole Ratio \\
\hline Prototype $(7 \mathrm{MPa})$ & 366 & $37.2 \%$ & 3.22 \\
\hline Scaled-down (0.515 MPa) & 406.2 & $42.4 \%$ & 1.85 \\
\hline Scaled-down (0.470 MPa) & 394.7 & $37.1 \%$ & 2.21 \\
\hline Scaled-down (0.377 MPa) & 374.0 & $26.5 \%$ & 3.21 \\
\hline Scaled-down (0.337 MPa) & 366.0 & $21.9 \%$ & 3.81 \\
\hline Scaled-down (0.308 MPa) & 360.5 & $18.7 \%$ & 4.34 \\
\hline Scaled-down (0.207 MPa) & 342.6 & $7.2 \%$ & 7.43 \\
\hline Scaled-down (0.101 MPa) & 660.5 & $0.0 \%$ & 16.36 \\
\hline
\end{tabular}


Table 15

Scaled-down test facility as-built dimensions and specifications

\begin{tabular}{ll}
\hline Dimension/Specification & Main Test Vessel \\
\hline Vessel Material & Stainless Steel 316 \\
Pressure Vessel Rating & $0.343 \mathrm{MPa}$ at $538^{\circ} \mathrm{C}$ \\
Hot duct length $(\mathrm{m})$ & 0.254 \\
Hot duct diameter $(\mathrm{m})$ & 0.191 \\
Graphite cylinder diameter $(\mathrm{m})$ & 0.051 \\
Graphite cylinder pitch $(\mathrm{m})$ & 0.088 \\
Hot plenum diameter $(\mathrm{m})$ & 0.851 \\
Hot plenum height $(\mathrm{m})$ & 0.359 \\
\hline & Containment Vessel \\
\hline Vessel Material & Stainless Steel 304 \\
Pressure Vessel Rating & $0.170 \mathrm{MPa}$ at $100^{\circ} \mathrm{C}$ \\
Vessel Inner Diameter $(\mathrm{m})$ & 0.905 \\
Vessel Free Height $(\mathrm{m})$ & 1.657 \\
Vessel Free Volume $\left(\mathrm{m}^{3}\right)$ & 1.049 \\
\hline
\end{tabular}


Table 16

Instrumentation of the scaled-down test facility

\begin{tabular}{llcl}
\hline Parameter Measured & Instrument & $\begin{array}{l}\text { Number of } \\
\text { Measurement Locations }\end{array}$ & $\begin{array}{l}\text { Height of Hot Exit } \\
\text { Plenum or Hot Duct } \\
\text { Covered }\end{array}$ \\
\hline $\mathrm{O}_{2}$ Concentration & \multicolumn{2}{c}{ Main Test Vessel } & \\
Pressure & \multicolumn{4}{c}{$\begin{array}{l}\text { Oxygen Analyzer Probe } \\
\text { Temperature }\end{array}$} & Gauge Pressure Transmitter & 10 & $0.359 \mathrm{~m} / 0.359 \mathrm{~m} \mathrm{\&}$ \\
\hline & K-type Thermocouple Probe & 40 & $0.1905 \mathrm{~m} / 0.1905 \mathrm{~m}$ \\
$\mathrm{O}_{2}$ Concentration & Containment Vessel & $0.359 \mathrm{~m} / 0.359 \mathrm{~m}$ \\
Pressure & Oxygen Analyzer Probe & 1 & $0.359 \mathrm{~m} / 0.359 \mathrm{~m}$ \\
Temperature & Gauge Pressure Transmitter & 1 & N/A \\
\hline
\end{tabular}




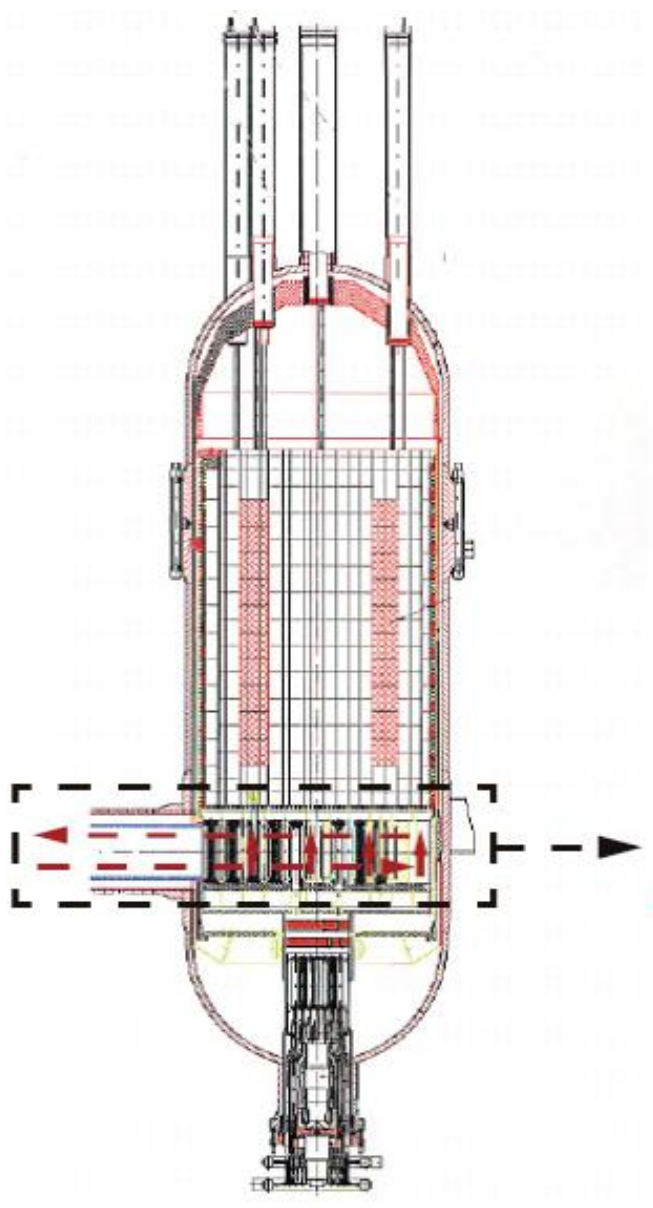

(a)
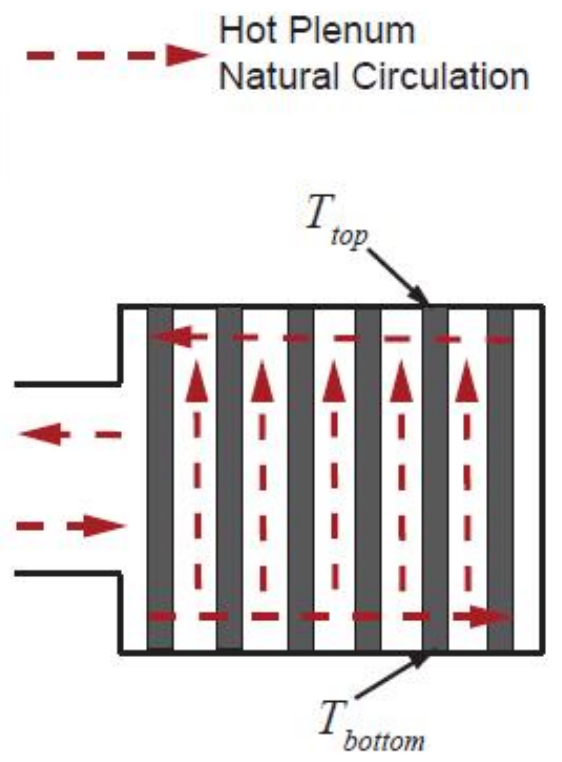

(b)

Fig. 1. (a) GT-MHR reactor vessel and (b) enlarged hot duct-hot exit plenum system 


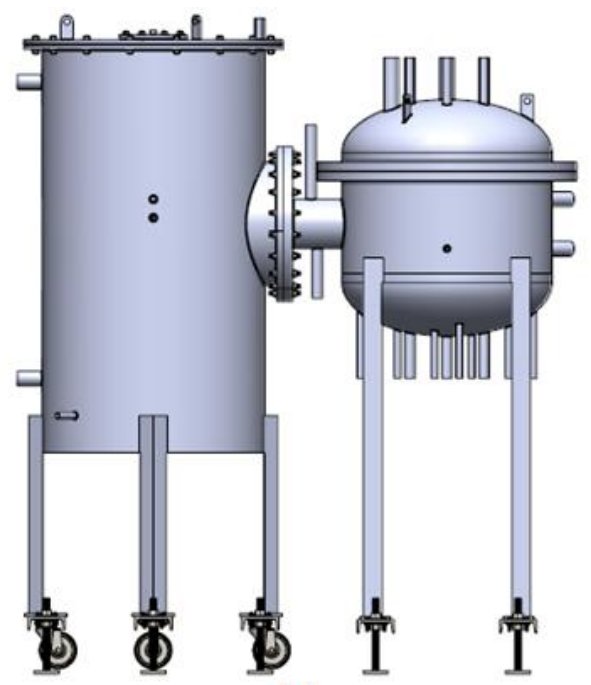

(a)

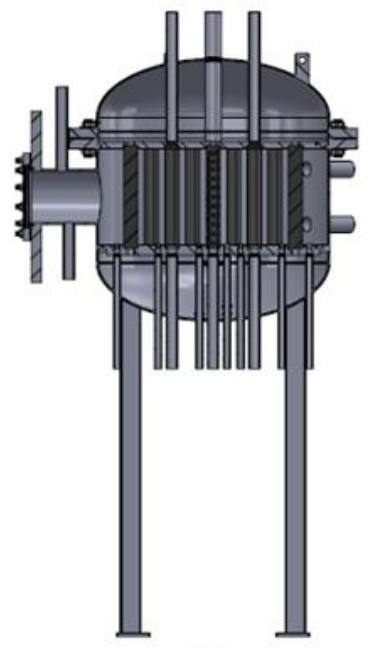

(b)

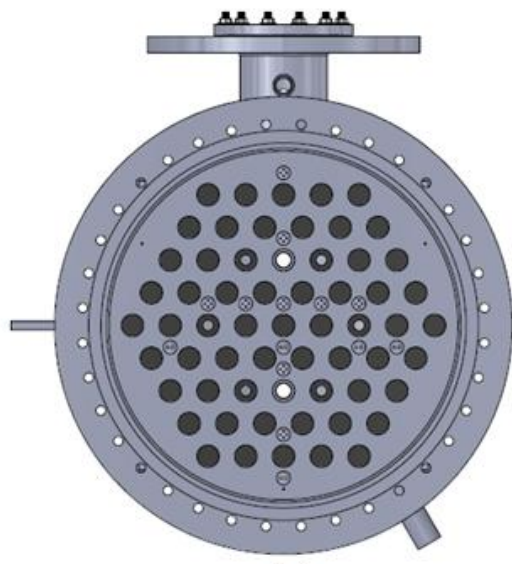

(c)

Fig. 2. (a) Side view of scaled-down test facility (b) cut view of main test vessel and (c) top view of hot exit plenum in main test vessel 


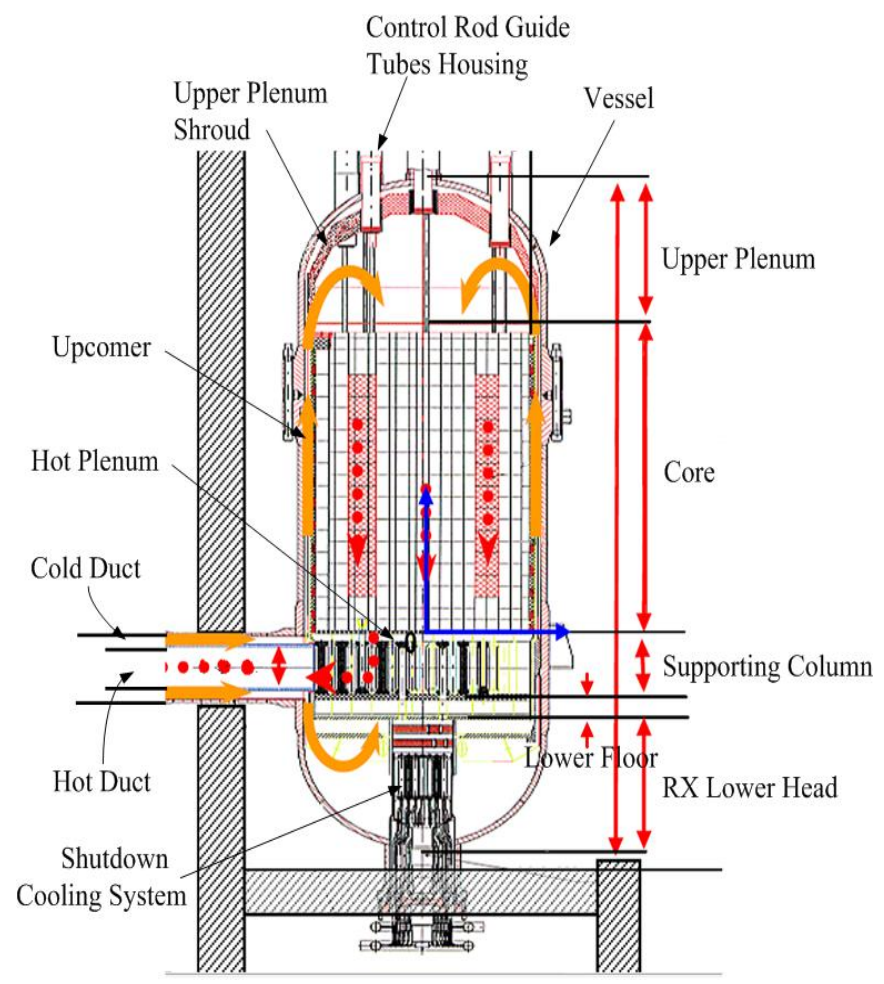

Fig. 3. The gas-turbine modular helium reactor with key parameters indicated 


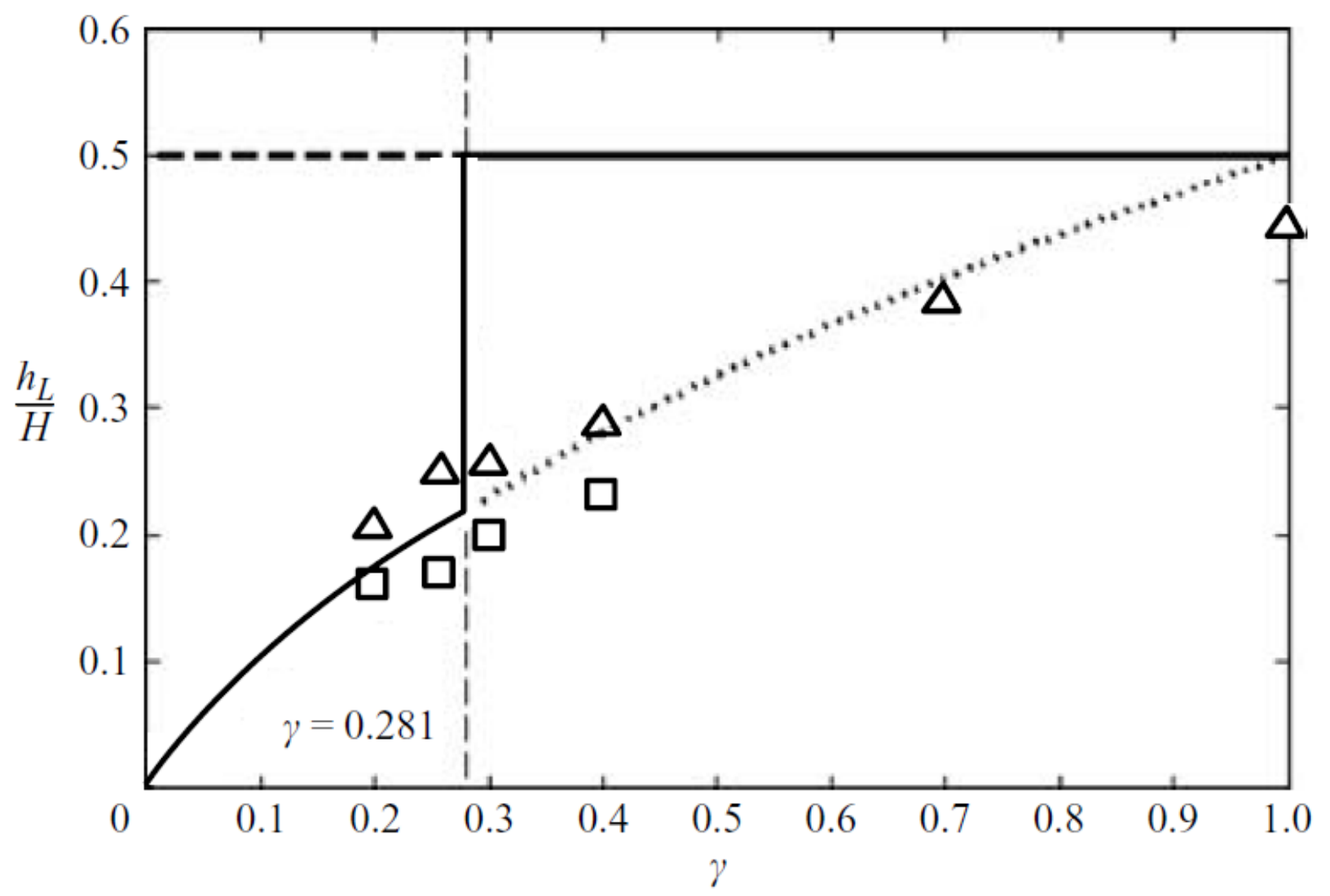

Fig. 4. Flow depth of the heavy current (Lowe et al., 2005) 


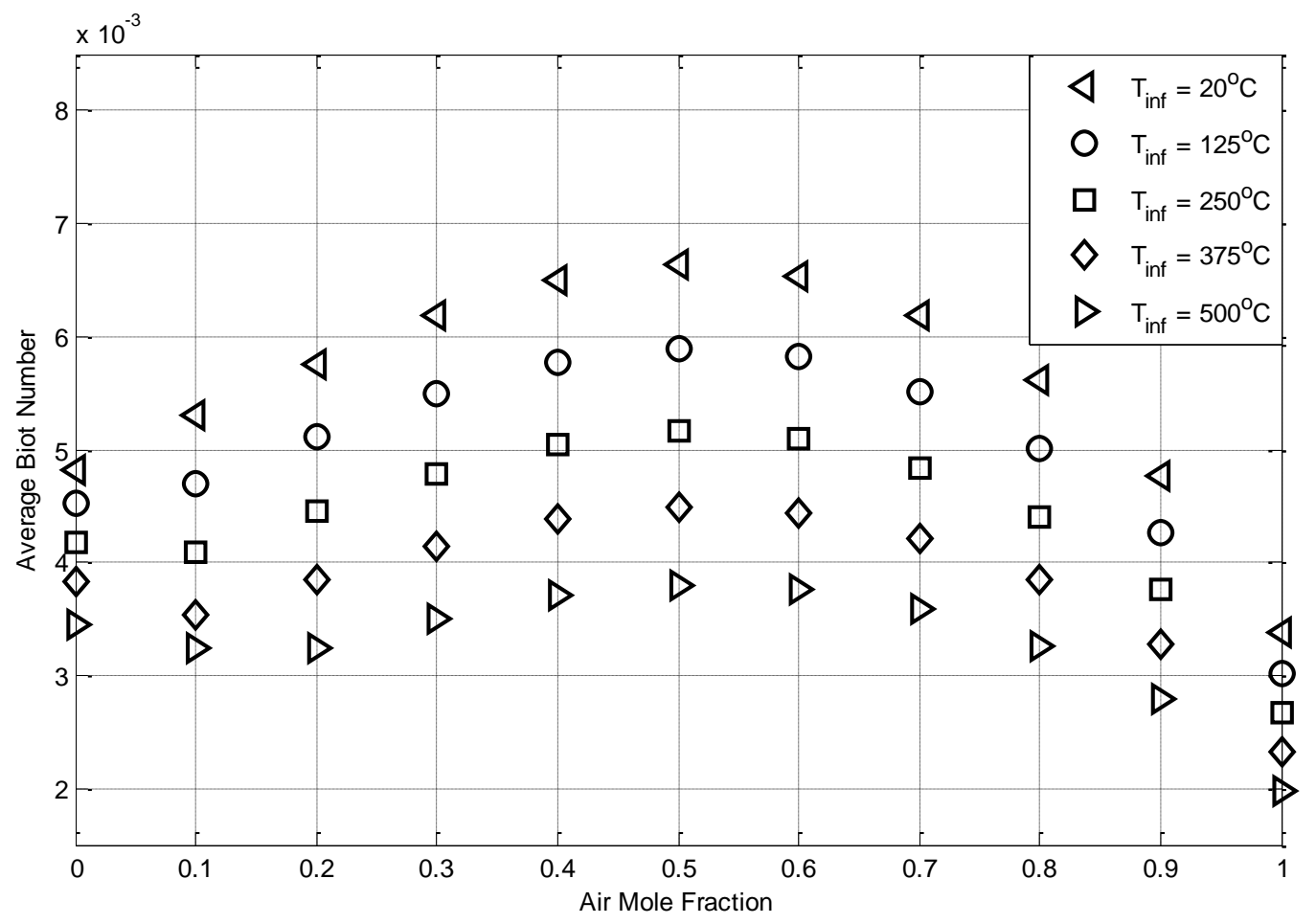

Fig. 5. Average Biot numbers for prototypic conditions 


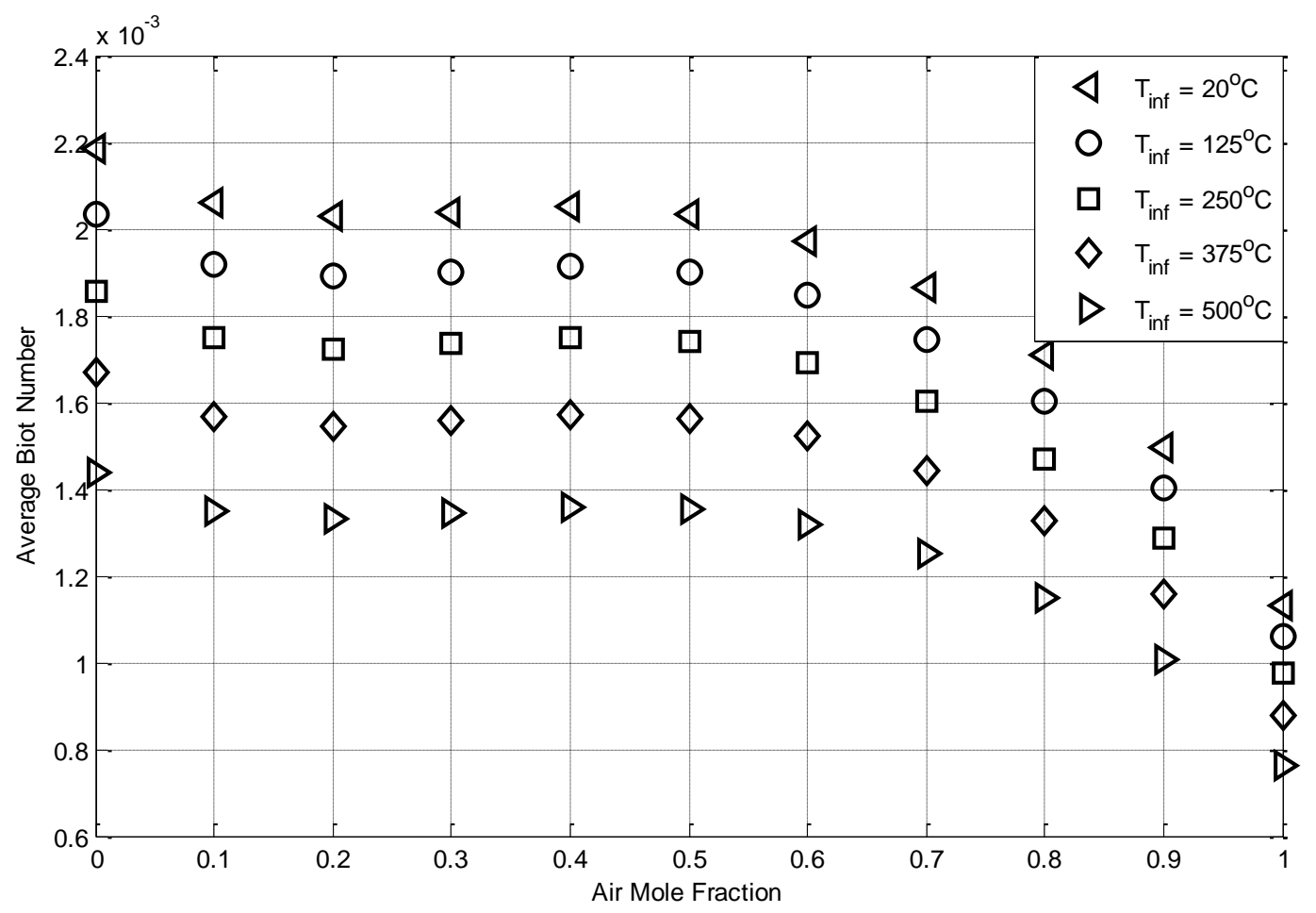

Fig. 6. Average Biot numbers for scaled-down conditions 


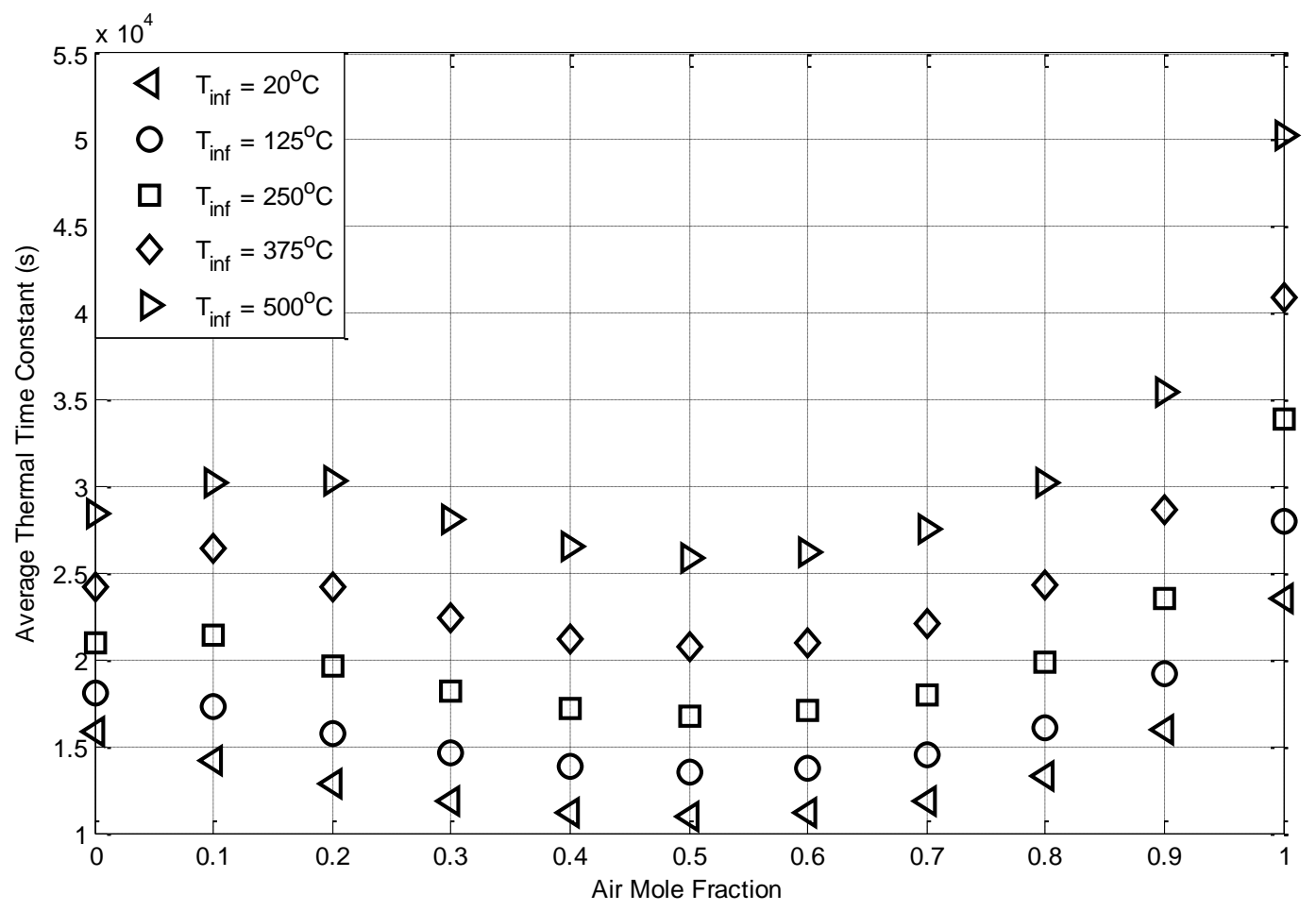

Fig. 7. Average thermal time constant for prototypic conditions 


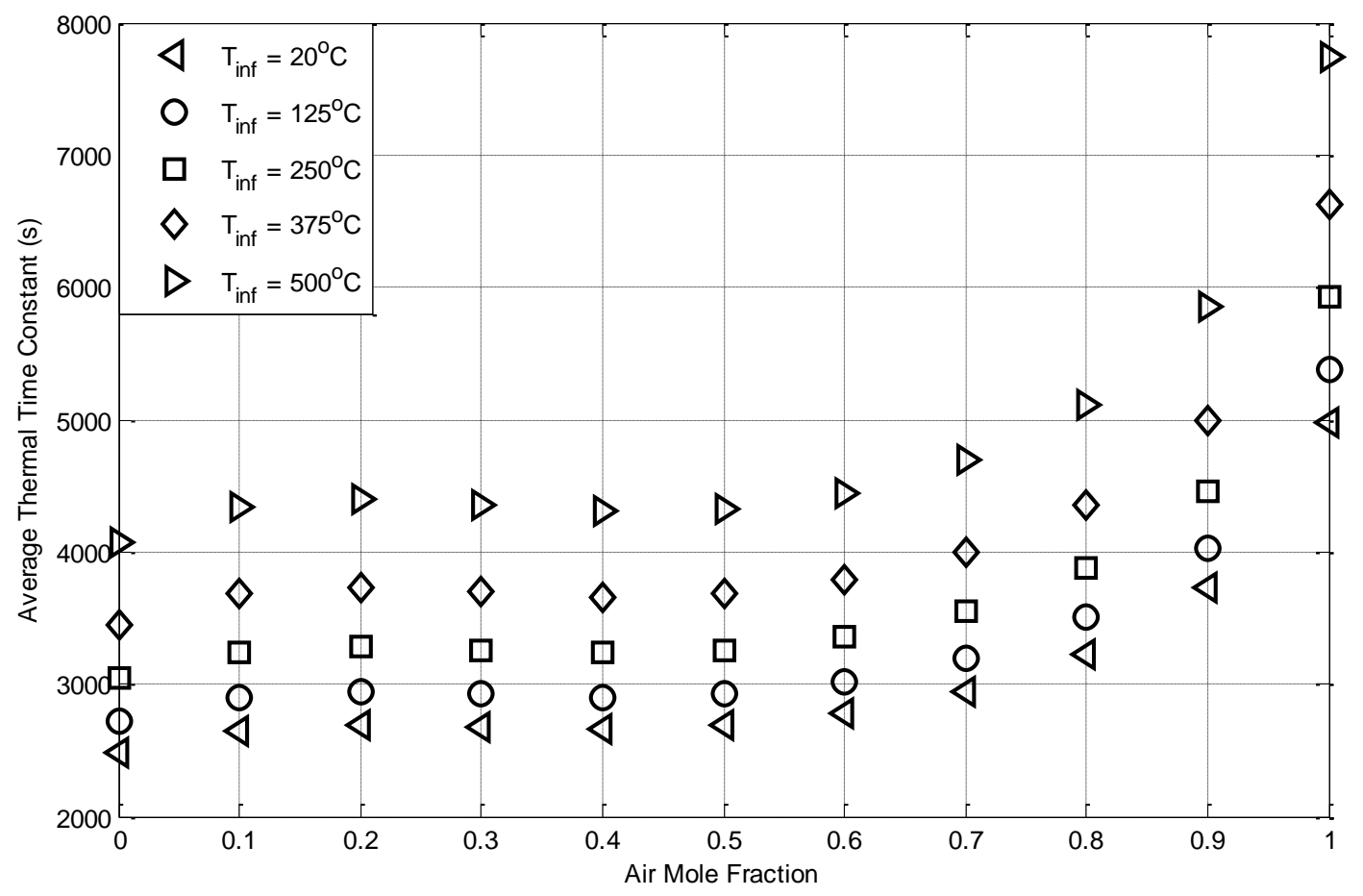

Fig. 8. Average thermal time constant for scaled-down conditions 


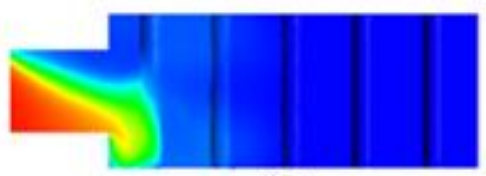

(a)

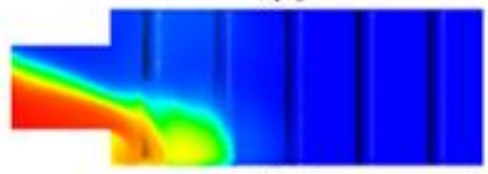

(b)

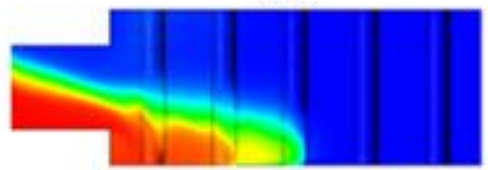

(c)

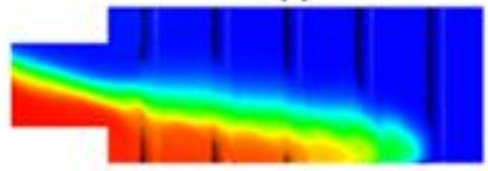

(d)

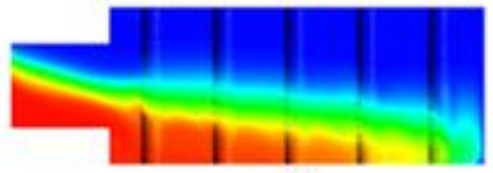

(e)

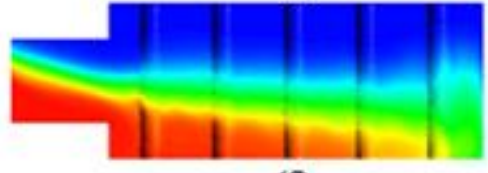

(f)

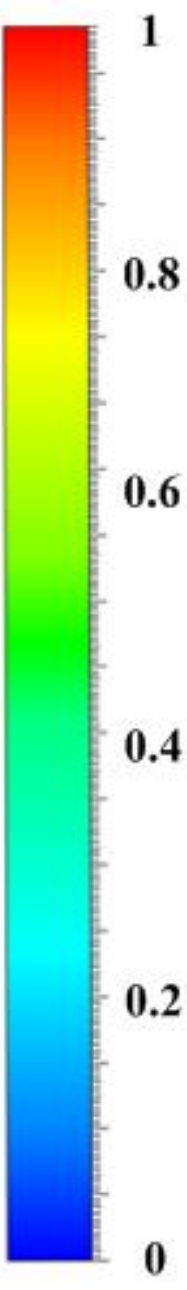

Fig. 9. Progression of air plume during a density-driven air ingress event in the test section at time: (a) $t=0.6 \mathrm{~s}$, (b) $t$ $=1.1 \mathrm{~s}$, (c) $t=1.85 \mathrm{~s}$, (d) $t=3.1 \mathrm{~s}$, (e) $t=4.1 \mathrm{~s}$, and (f) $t=4.6 \mathrm{~s}$ following the break initiation 


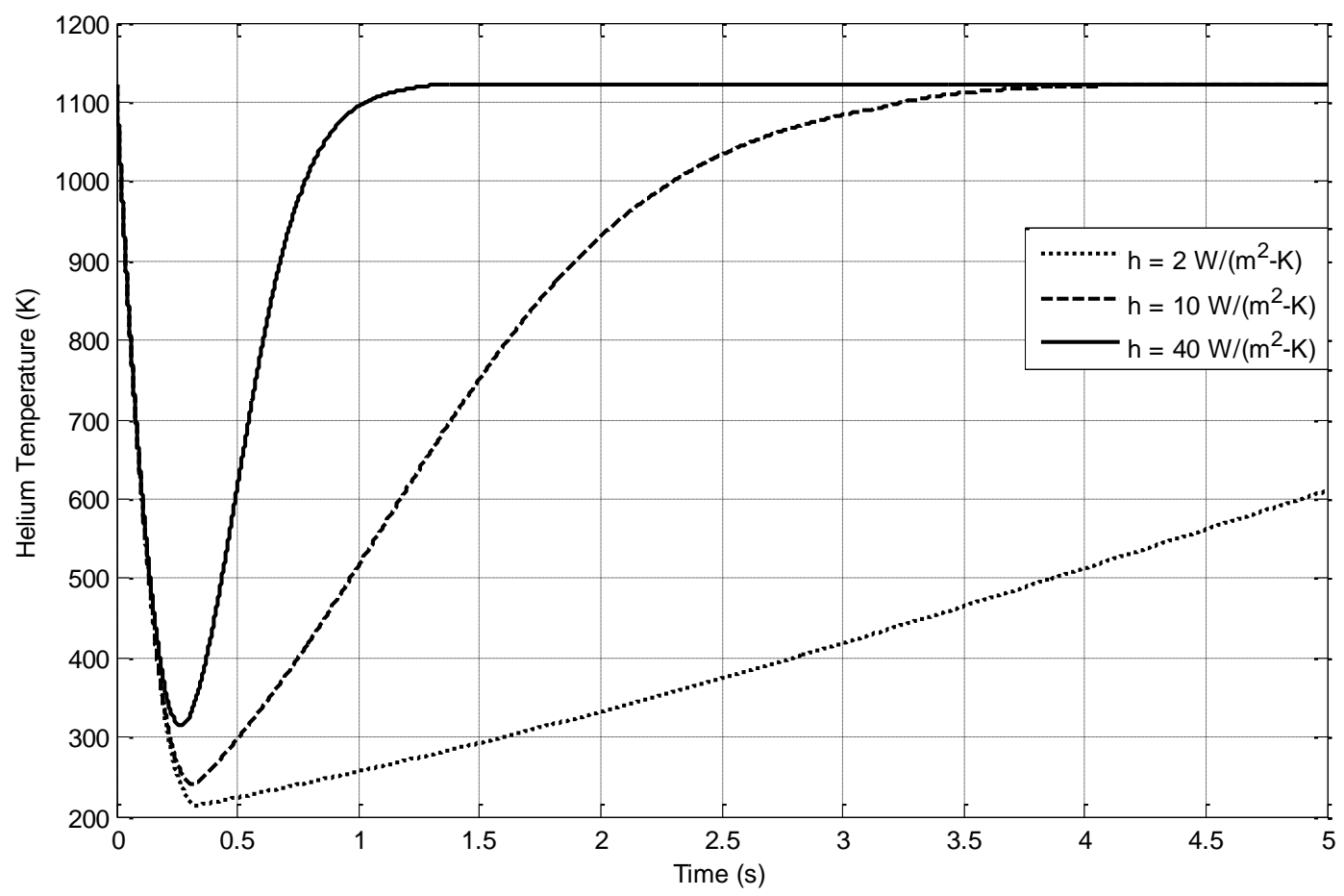

Fig. 10. Helium temperature versus time during depressurization of the prototypic vessel 


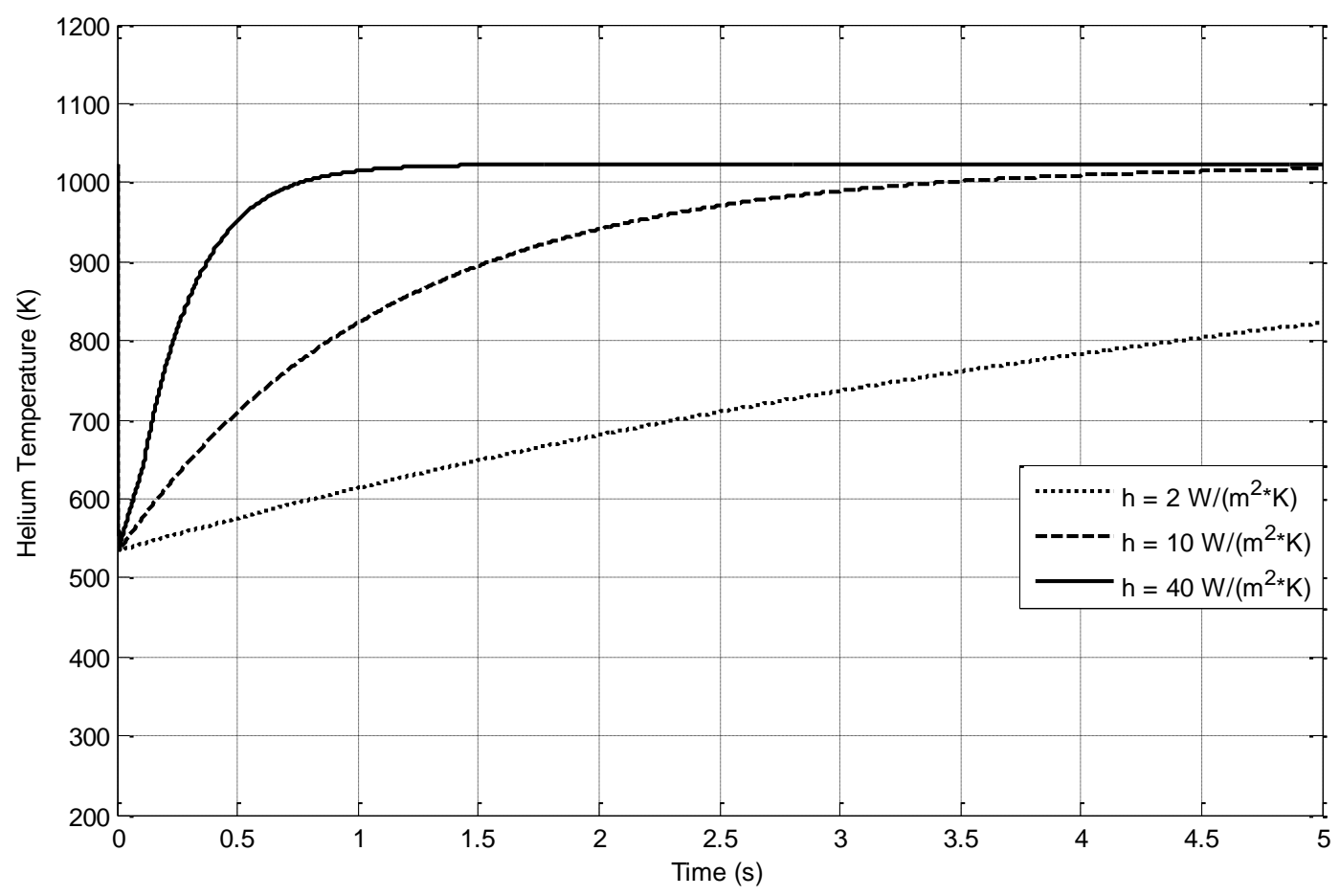

Fig. 11. Helium temperature versus time during depressurization of the scaled-down facility 


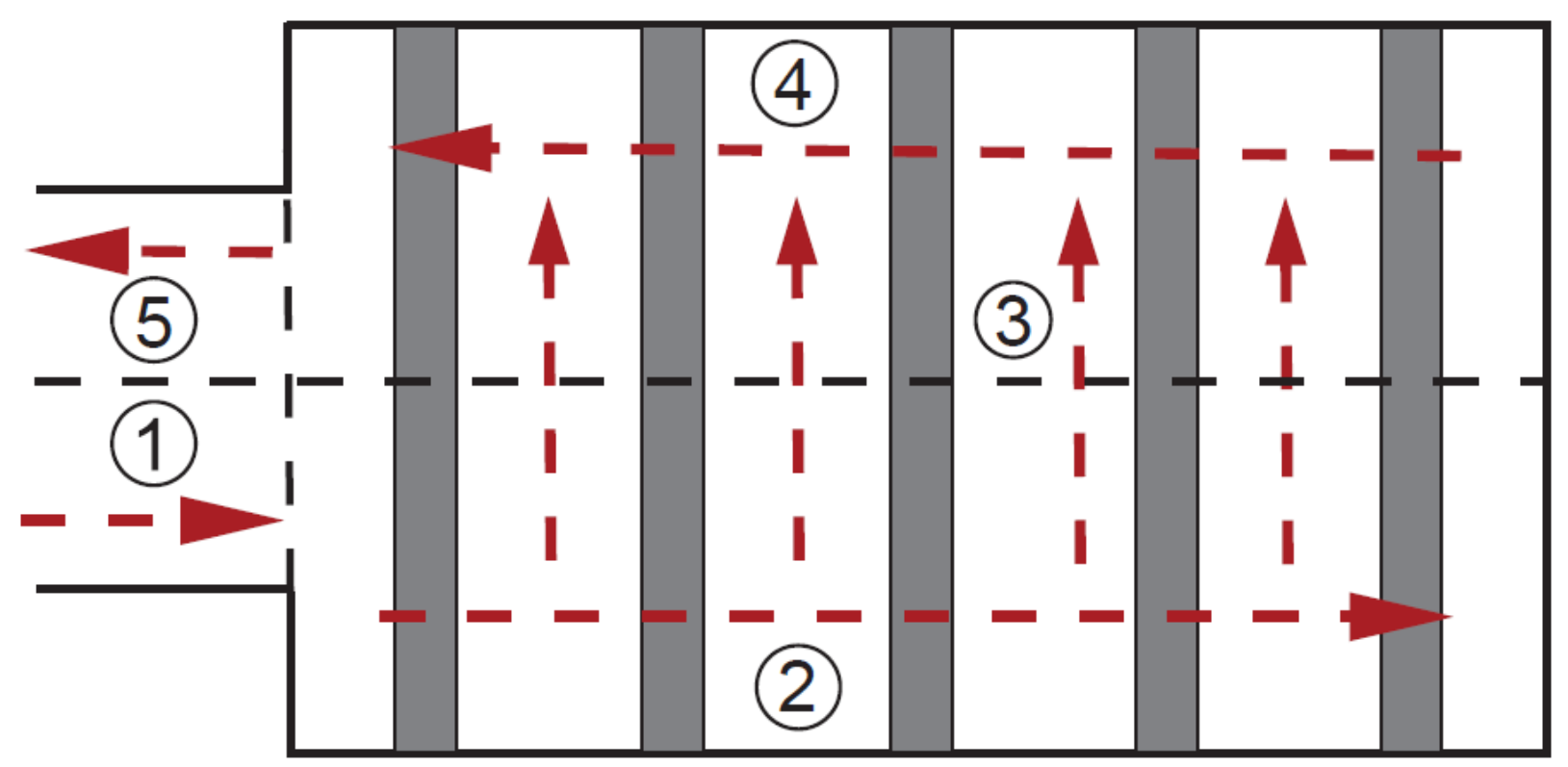

Fig. 12. Hot duct-hot exit plenum system with control volumes outlined 


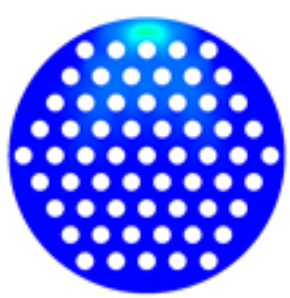

(a)

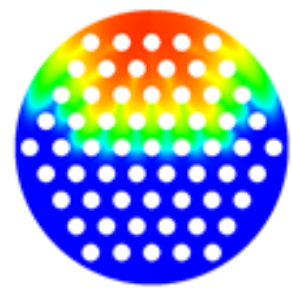

(c)

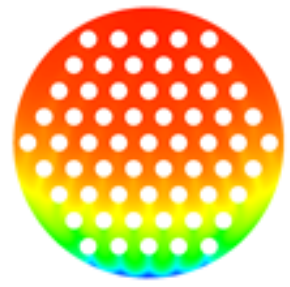

(e)

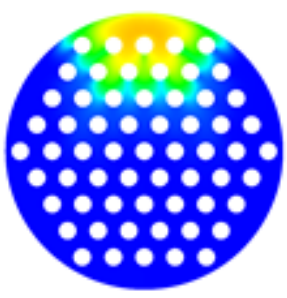

(b)

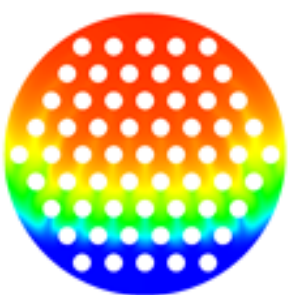

(d)

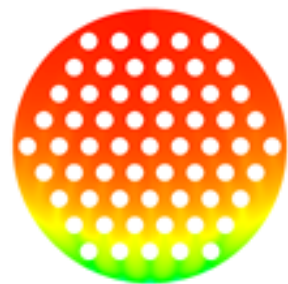

(f)

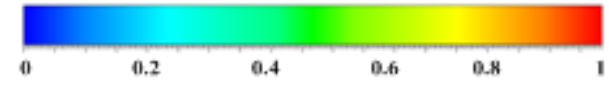

Fig. 13. Overhead view of the propagation of the air plume at the bottom of the test section at time: (a) $t=0.6 \mathrm{~s}$, (b) $t$ $=1.1 \mathrm{~s}$, (c) $t=1.85 \mathrm{~s}$, (d) $t=3.1 \mathrm{~s}$, (e) $t=4.1 \mathrm{~s}$, and (f) $t=4.6 \mathrm{~s}$ following the break initiation 


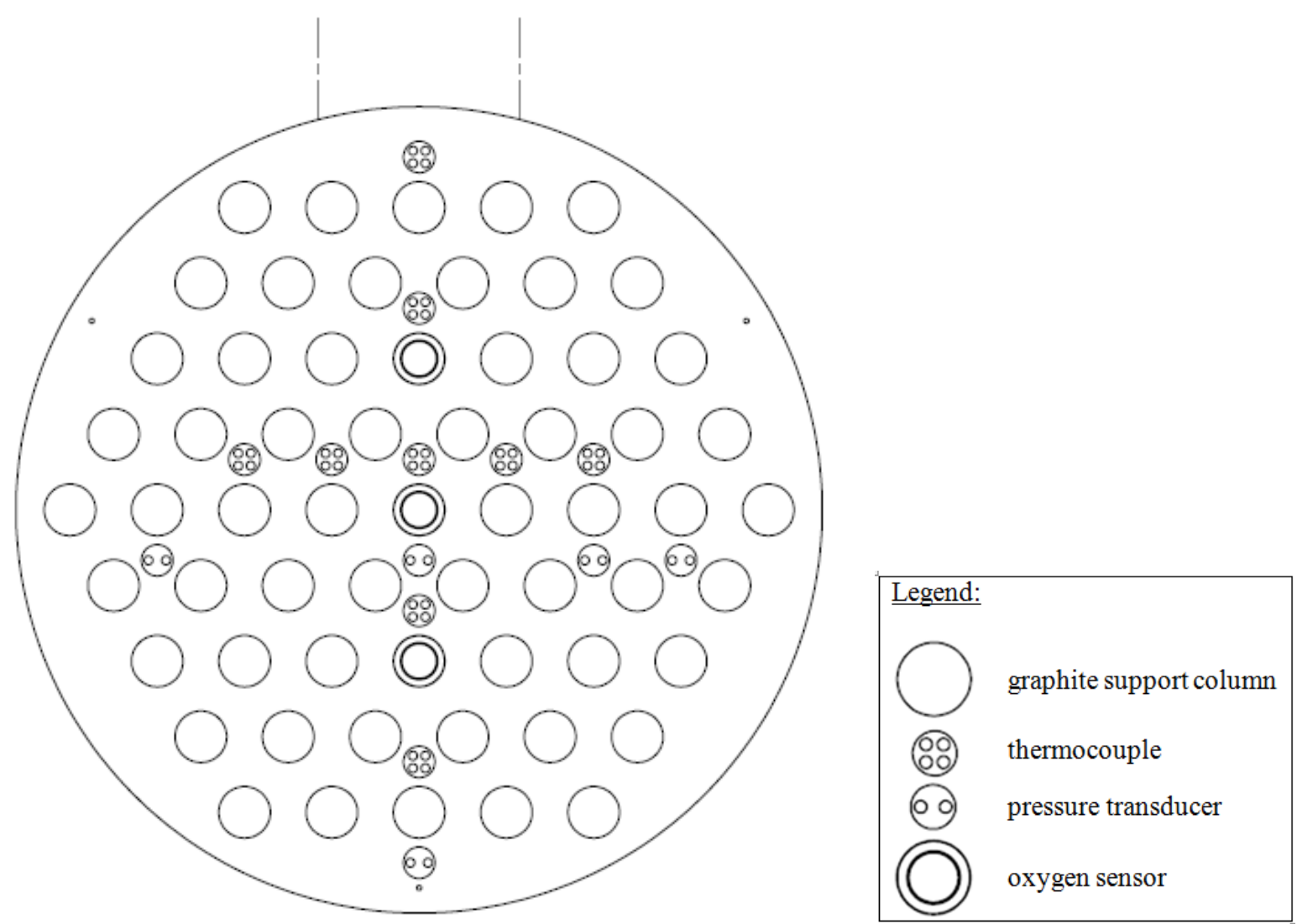

Fig. 14. Top view of bottom plate with instrumentation ports to measure initial air ingress plume 


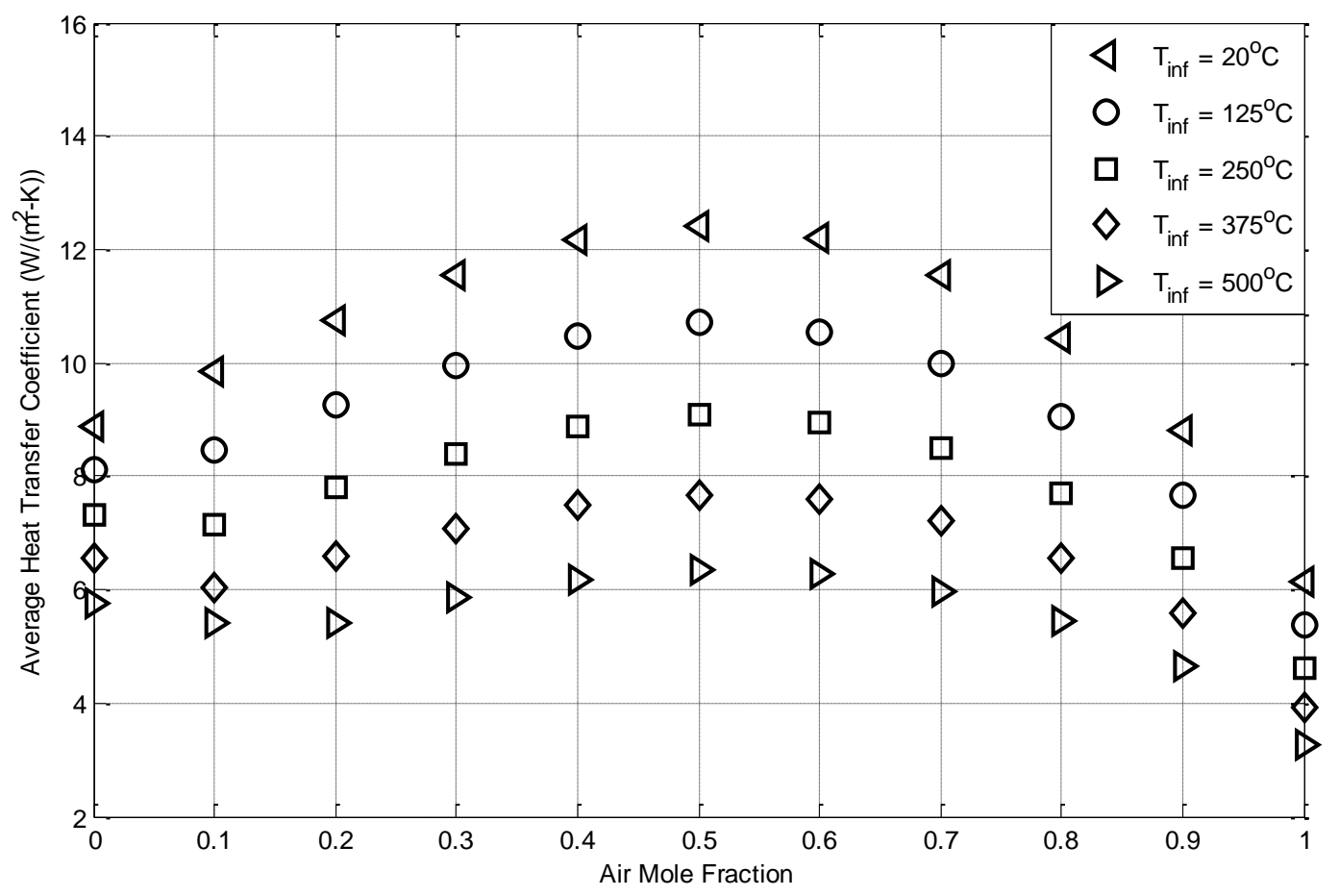

Fig. 15. Average heat transfer coefficient vs. air mole fraction for the prototype geometry 


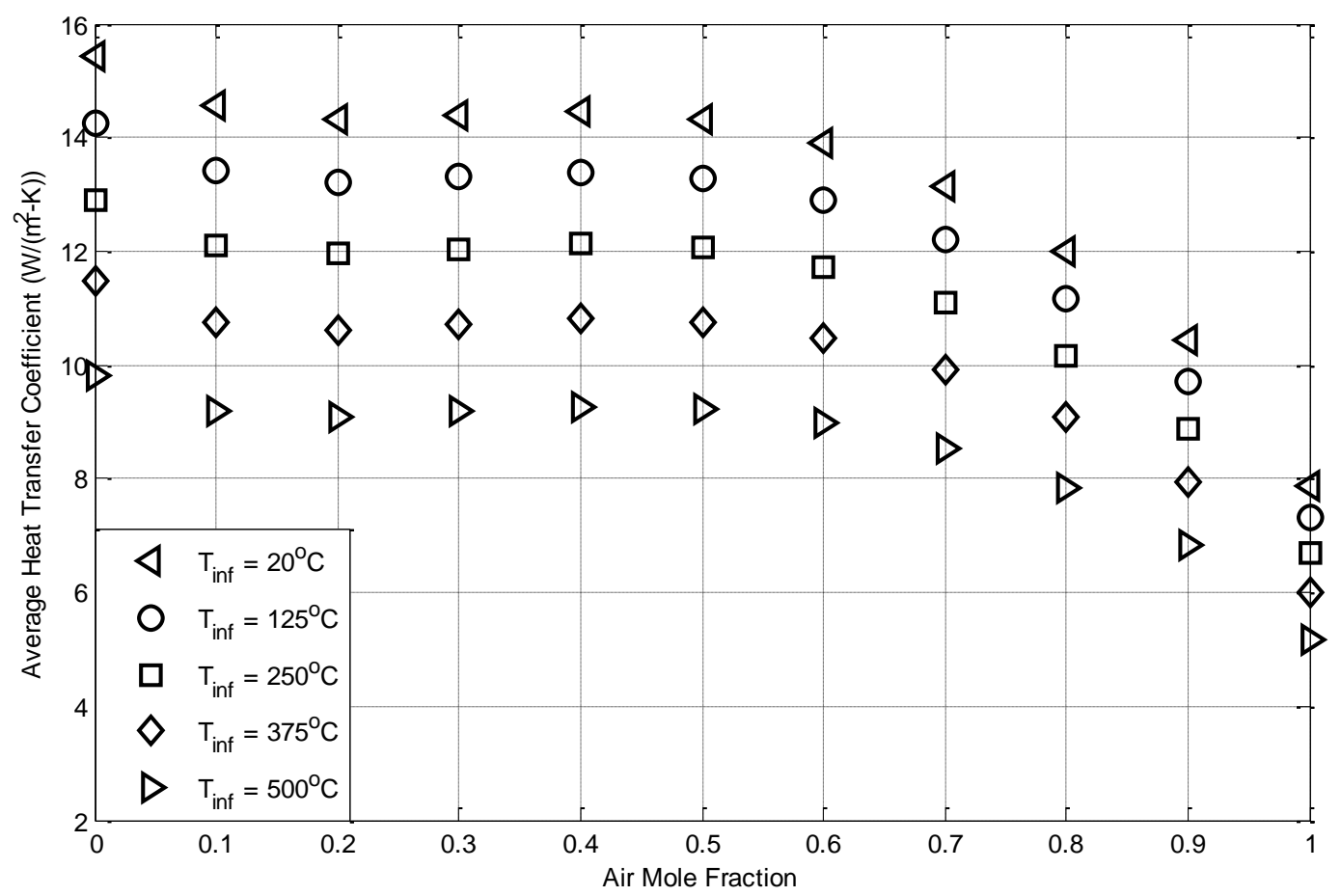

Fig. 16. Average heat transfer coefficient vs. air mole fraction for the scaled-down geometry 


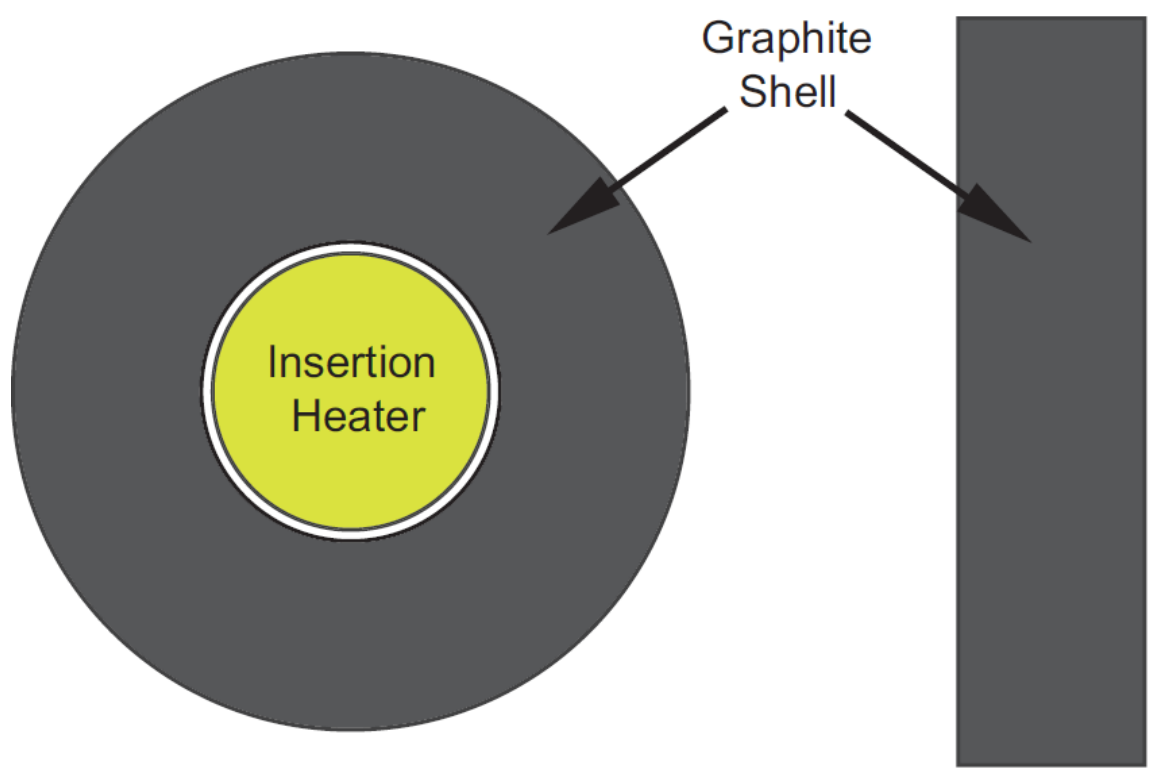

(a)

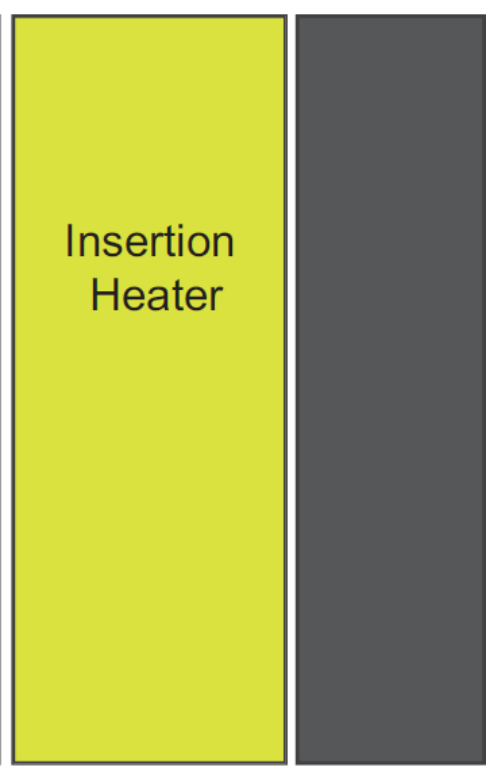

(b)

Fig. 17. (a) Overhead view of case (C) and (b) Side cut view of scaled-down shell/heater system of case (C) 


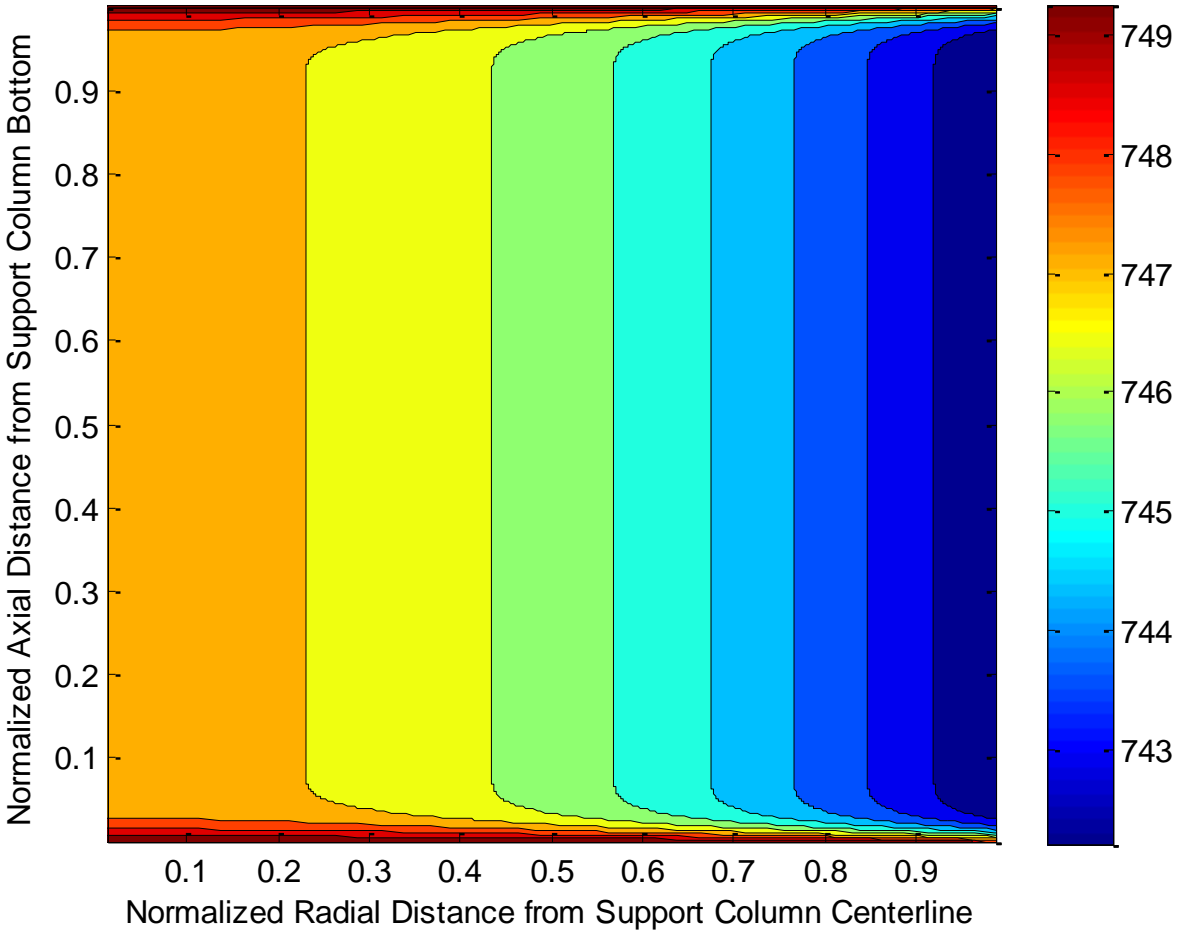

Fig. 18. Temperature contour plot for prototypic support column (Case A) at $t=6 \tau_{\text {total }}$ 


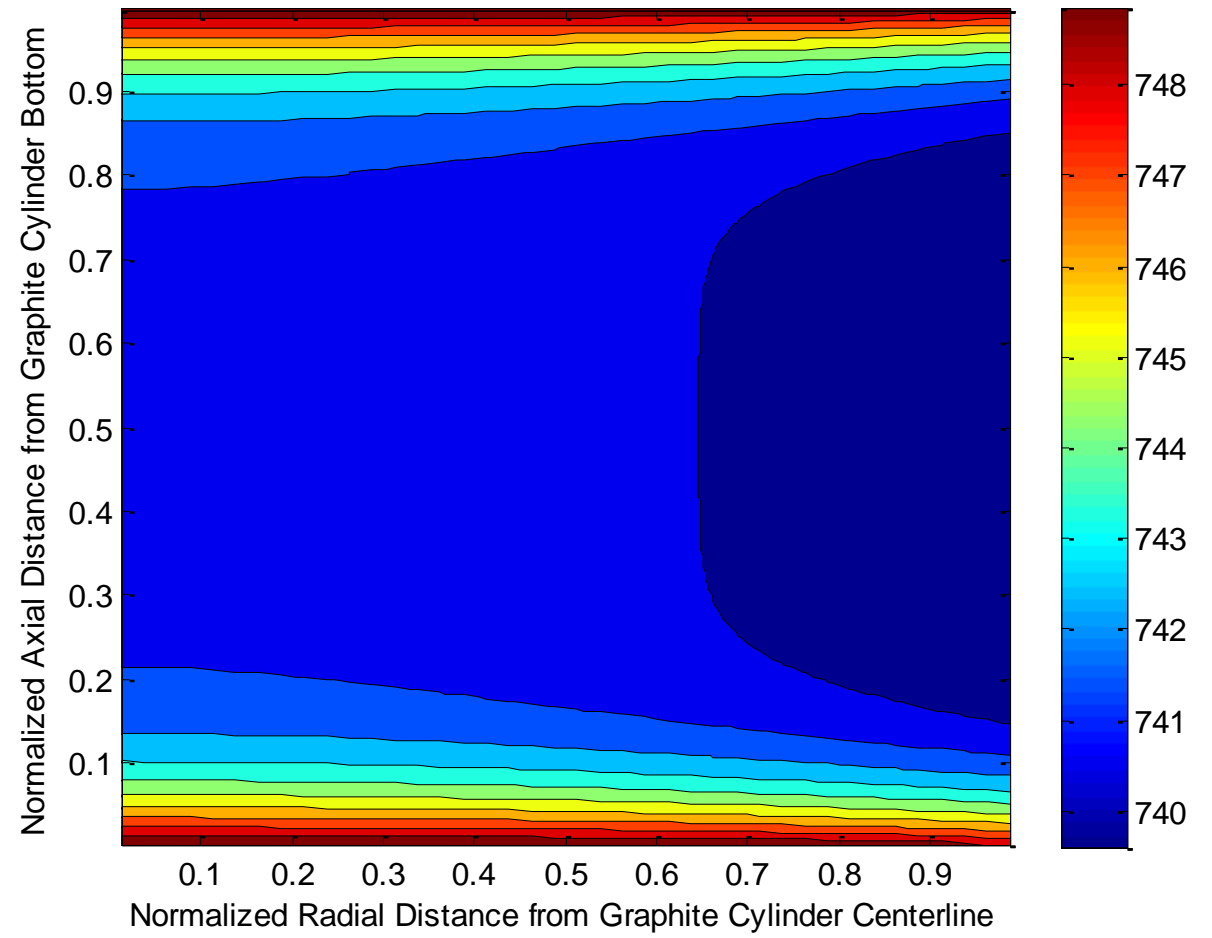

Fig. 19. Temperature contour plot of scaled-down test facility graphite cylinder (Case B) at $t=6 \tau_{\text {total }}$ 


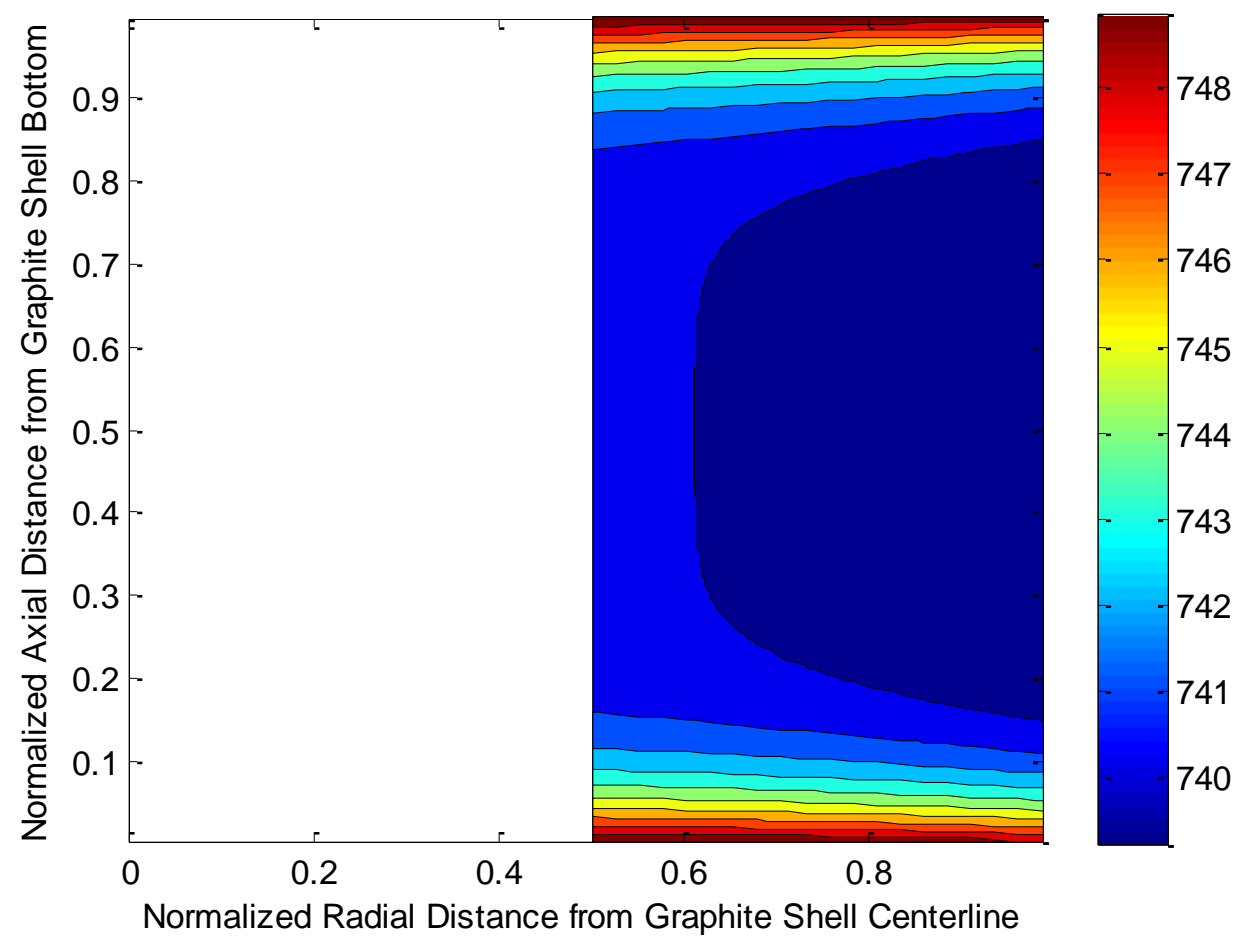

Fig. 20. Temperature contour plots of scaled-down test facility shell/heater system for $125 \mathrm{~W}$ (Case C) at $t=6 \tau_{\text {total }}$ 